\title{
On the Weakening of Northward Propagation of Intraseasonal Oscillations During Positive Indian Ocean Dipole Events.
}

\author{
Aditya Kottapalli ( $\sim$ adityak1@iisc.ac.in ) \\ Indian Institute of Science https://orcid.org/0000-0001-5933-3940 \\ Vinayachandran P N \\ Indian Institute of Science
}

\section{Research Article}

Keywords: IOD, DMI, moisture mode, moist entropy, SST.

Posted Date: July 12th, 2021

DOI: https://doi.org/10.21203/rs.3.rs-580203/v1

License: (c) (i) This work is licensed under a Creative Commons Attribution 4.0 International License.

Read Full License

Version of Record: A version of this preprint was published at Climate Dynamics on February 15th, 2022. See the published version at https://doi.org/10.1007/s00382-022-06164-w. 


\section{Authors:}

13 Aditya Kottapalli and Vinayachandran P N.

14

\section{Affiliation:}

16 Centre for Atmospheric and Oceanic Sciences \& Divecha Centre for Climate Change, Indian Institute of 17 Science, Bengaluru, India.

18

19

\section{${ }^{\text {a Corresponding author: }}$}

20

adityak1@iisc.ac.in.

21

22

23

24

25

26

27

28

29

30

31

32

33

34

35

36

37 


\section{Abstract}

42 The northward propagation of intraseasonal oscillations (ISO) is one of the major modes of variability in the 43 tropics during boreal summer, associated with active and break spells of monsoon rainfall over the Indian region, 44 and modulate the Indian summer monsoon rainfall (ISMR). The northward march starts close to the equator over 45 warm waters of the Indian Ocean and continues till the foothills of the Himalayas. The northward propagations 46 tend to be weaker during positive Indian Ocean Dipole (pIOD) years. We have used the "moisture mode" 47 framework to understand the processes responsible for the weakening of northward propagations during IOD 48 years. Our analyses show that moistening caused by the horizontal advection was the major contributor for the 49 northward propagations during negative IOD (nIOD) years, and its amplitude is much smaller during pIOD years. 50 The reduction in the zonal advection during pIOD is responsible for the weakening of northward propagations. 51 Also, the mean structure of entropy between $925 \mathrm{hpa}-500 \mathrm{hpa}$ levels remained similar over most of the monsoon 52 region across the contrasting IOD years. The reason for weaker northward propagations can be attributed to the weaker zonal wind perturbations at intraseasonal timescales. The weaker zonal wind perturbations during ISO

54 events in pIOD years owing to cooler sea surface temperatures (SST) in the South-East Equatorial Indian Ocean 55 (SEIO) and warmer West Equatorial Indian Ocean (WEIO) and South-East Arabian Sea (SEAS) is proposed to 56 be the possible reason for the weakening of northward propagations during pIOD years.

58 Key Words: IOD, DMI, moisture mode, moist entropy, SST. 
60 Funding: A.K has financial support from MHRD Government of India (GOI) and Grantham fellowship. P.N.V

61 has partial financial support from J C Bose National Fellowship, SERB, DST, Government of India (GOI) and

62 BoBBLE program funded by Ministry of Earth Sciences, Govt. of India under its Monsoon Mission program.

63 Availability of data: The data used in this study can be downloaded from

64 https://psl.noaa.gov/data/gridded/data.ncep.reanalysis2.html,

65 https://psl.noaa.gov/data/gridded/data.noaa.oisst.v2.highres.html, $\quad$ http://oaflux.whoi.edu/data.html and

66 https://psl.noaa.gov/data/gridded/data.interp_OLR.html

67 Code Availability: All the codes used in this study were written in NCAR Command Language (NCL). Though

68 they are written specifically for this study, they will be provided to anyone on a request to the author through an 69 e-mail.

70 Competing Interests: Authors declare no competing interests.

71

72

73

74

75

76

77

78

79

80

81

82

83

84

85

86

87

88

89

90

91

92

93

94

95

96

97 
The northward propagations of cloud bands from the equator over to the monsoon regions of southeast Asia are associated with the active and break spells of the Indian monsoon (Yasunari (1979), Sikka and Gadgil

102 (1980), Krishnamurti (1982)). Using daily satellite mosaic pictures, Yasunari (1979) found two dominant periodicities in cloudiness fluctuations, of 40 days and 15 days, out of which the 40 - day fluctuations showed marked northward movement of cloudiness from equatorial zone to mid-latitudes. This northward movement was most apparent in the Indian Ocean sector. Sikka and Gadgil (1980), using satellite images along with $700 \mathrm{mb}$ trough data, found that there were two favourable locations for maximum cloud zone (MCZ) during summer monsoon, one over the monsoon zone to the north of $15^{\circ} \mathrm{N}$ latitude and the other over the equatorial region $\left(0^{\circ} \mathrm{N}\right.$ $-10^{\circ} \mathrm{N}$ ). They observed that the MCZ over the monsoon zone could not survive for a long time without being reestablished by MCZ over the ocean by the northward propagation. Krishnamurti (1982) analyzed wind fields at

110 850hpa during the summer monsoon experiment (MONEX) and confirmed the existence of a peak in $30-50$

111 days' time range. They also illustrated the propagation of trains of troughs and ridges from the equator to the

112 Himalayas. They found that the meridional scale of propagation was around $3000 \mathrm{~km}$ and speed was about $0.75^{\circ}$ 113 to $1^{\circ}$ per day.

114 Considerable efforts were made in the last five decades to understand the mechanisms responsible for 115 the northward propagations. Webster (1983) suggested the poleward gradient of sensible heat flux in the boundary

116 layer to be responsible for northward propagations. The emanation of equatorial Rossby waves from Madden 117 Julian Oscillation (MJO) was proposed to be responsible for northward propagations by some studies (e.g., Xie 118 and Wang (1997), Lawrence and Webster (2002)). Jiang et al. (2004) proposed that in the presence of the vertical 119 shear, barotropic vorticity develops in the atmosphere ahead of the convection centre. This barotropic vorticity 120 induces convergence in the boundary layer through Ekman pumping, leading to a northward shift of convective 121 heating.

Along with the convection, the SST also show the intraseasonal oscillation signal (Krishnamurti et al.

123 (1988), Sengupta and Ravichandran (2001), Sengupta et al. (2001), Bhat et al. (2001)). Though the SST signals 124 could result from atmospheric forcing, they help enhance convergence to the north of the convection centre, hence 125 guiding the northward propagations (Sengupta et al. (2001)). Fu et al. (2003), through their model experiments, 126 found that the atmosphere only models could not simulate the northward propagations even when forced with 127 daily SSTs from the coupled run, suggesting the role of high-frequency air-sea interactions in northward 128 propagations.

129 The SSTs over the equatorial Indian Ocean are modulated by Indian Ocean Dipole (IOD) (Saji et al. 130 (1999), Webster et al. (1999)), which is a coupled Ocean atmospheric phenomenon that is manifested by the 131 anomalous warming (cooling) of the Eastern equatorial Indian Ocean (EEIO) and simultaneous cooling (warming) 132 of the western equatorial Indian Ocean (WEIO). In its positive phase, WEIO is anomalously warmer than EEIO 133 and vice versa. Since northward propagations start close to the equator, it is interesting to ask, "How would IOD 134 affect the northward propagations?" Though the IOD peaks after the monsoon, the SST anomalies in the 135 equatorial Indian ocean shows a signal during the monsoon time itself. Ashok et al. (2001) found that IOD plays 136 a vital role in modulating the ISMR and influences the ISMR - EINino and the Southern Oscillation (ENSO) 137 relation. Gadgil et al. (2004) noticed that larger anomalies in the ISMR are linked with the Equatorial Indian ocean 138 oscillation (EQUINOO), which can be considered as the atmospheric component of the coupled IOD. The impact 
139 of IOD on global climate was explored by Saji and Yamagata (2003). They noted the impact of IOD on several 140 regions even that are remote to the Indian Ocean with strong correlations over Europe, northeast Asia, North and 141 South America and South Africa co-occurring with IOD events. A review of relationship between IOD and the 142 regional climate over the Indian Ocean and surrounding landmass was given in Vinayachandran et. al (2010). 143 They documented that IOD events affects the rainfall over maritime continent, Australia, Indian subcontinent, and 144 East Africa. While the maritime continent and Australia experience a deficit in rainfall during pIOD years, the 145 East Africa and India experiences excess rainfall.

146 Ajayamohan et al. (2008) investigated the role of IOD in modulating the northward propagations and 147 found out the coherent (incoherent) nature of propagations during negative (positive) IOD years. They also found 148 that the dynamical features suggested by Jiang et al. (2004) necessary for northward propagation were absent 149 during pIOD years leading to incoherent northward propagations. According to them, the mean structure of 150 specific humidity in SEIO undergoes radical changes during contrasting IOD years, and the meridional gradient 151 of specific humidity is enhanced (suppressed) during nIOD (pIOD) years leading to coherent (incoherent) 152 propagations. However, observations show that the meridional gradient of specific humidity between $5^{\circ} \mathrm{S}$ and the 153 equator was higher during pIOD years. Thus, it is not clear why northward propagations are incoherent during 154 pIOD years. Also, the processes responsible for this incoherent propagation during pIOD years remain 155 unexplored. Thus, this study's objective is to understand in detail "How would the northward propagations gets 156 modulated by the IOD?" and "What are the processes responsible for this modulation?".

157 To answer these questions, we use the "moisture mode" framework, which has been recently applied 158 extensively for understanding the eastward propagations of Madden Julian Oscillations (MJO) (e.g., Maloney 159 (2009), Sobel and Maloney (2012, 2013); Adames and Wallace (2015), Adames and Kim (2016)). It was revealed 160 from the past studies that the horizontal advection of moist static energy (MSE) is responsible for the eastward 161 propagation of MJO related convection (e.g., Maloney (2009), Jiang (2017)). In boreal winters, the maxima in the 162 mean specific humidity lie between $140^{\circ} \mathrm{E}-150^{\circ} \mathrm{E}$ longitudes close to the equator with the strong poleward and 163 westward gradients, which helps in the eastward propagation of MJO (Adames et al. (2016)). Jiang et al. (2018) 164 extended this moisture mode to northward propagations. They found that similar to the boreal winter, the boreal 165 summer's mean moisture structure is responsible for northward propagations. During boreal summer's, the 166 maximum in specific humidity is displaced to around $20^{\circ} \mathrm{N}$ over Indo - China region that leads to northward 167 propagation. Our analysis using the "moisture mode" framework to understand the differences in the northward 168 propagations during positive (pIOD) and negative IOD (nIOD) years revealed that the mean structure of the 169 specific humidity (entropy) does not change much across contrasting IOD years. On the other hand, we find that 170 the weakening of the northward propagations during pIOD years can be attributed to the weak perturbations of 171 zonal wind at intraseasonal time scales.

172 Our study in this paper is organized as follows: Section 2 describes the data used in our analysis. In 173 section 3, we discuss the methods used, along with some discussion on differences between pIOD and nIOD years. 174 Section 3.1 deals with method s used to identify pIOD and nIOD years. In section 3.2, we discuss the differences 175 in the mean structure between contrasting IOD years. Section 3.3 is dedicated to the methods used to visualize the 176 northward propagations and understanding the differences in the northward propagations across contrasting IOD 177 years. Section 4 exclusively deals with moist entropy and its budget. In section 5, we propose a possible 
mechanism that helps understand the weakening of northward propagation during pIOD years. Section 6 summarizes our analysis.

The Interpolated Outgoing Longwave Radiation (OLR) from the National Ocean and Atmospheric Administration (NOAA) (Liebmann and Smith (1996)) was used as a proxy for rainfall (Gadgil et al. (2002)). The air temperature, relative humidity, $\mathrm{u}$ - wind, $\mathrm{v}$ - wind and vertical pressure velocity were obtained from National Centres for Environmental Predictions (NCEP) reanalysis - 2 data provided by the NOAA/OAR/ESRL PSL, Boulder, Colorado, USA, from their Web site at https://psl.noaa.gov/data/gridded/data.ncep.reanalysis2.html was used. Both the OLR and reanalysis -2 data have a horizontal resolution of $2.5^{\circ} \times 2.5^{\circ}$, and there are 17 levels vertically from $1000 \mathrm{hpa}$ level to $10 \mathrm{hpa}$ level. High-resolution $0.25^{\circ} \times 0.25^{\circ} \mathrm{SST}$ anomaly data OISST (Huang (2020)) from NOAA was used for calculating the Dipole Mode Index (DMI) to categorize the IOD years based on the June - July - August - September (JJAS) mean DMI index (Saji et al. (1999)). The surface heat fluxes were taken from OAFlux (Yu et al. (2008)) with the spatial resolution of $1^{\circ} \times 1^{\circ}$. The OAFlux data was only available over oceans but, the residues from this error are small enough to be neglected (Jiang et al. (2018)). All the data used in the analysis has a temporal resolution of 1 day.

\section{Methods and Discussion:}

\subsection{Identifying pIOD and nIOD years:}

We start with differentiating the monsoon period (JJAS) into contrasting IOD (positive/negative) years. Following Saji et al. (1999), the strength of an IOD event is dete rmined using the Dipole Mode Index (DMI), defined as the difference in the area-averaged SST anomalies between the WEIO $\left(50^{\circ} \mathrm{E}-70^{\circ} \mathrm{E}, 10^{\circ}\right.$ $\left.\mathrm{S}-10^{\circ} \mathrm{N}\right)$ and EEIO $\left(90^{\circ} \mathrm{E}-110^{\circ} \mathrm{E}, 10^{\circ} \mathrm{S}-0\right)$ normalized by the standard deviation (SD). Since we are interested in the summer monsoon, the JJAS mean DMI is used for associating a particular monsoon period into positive IOD, negative IOD or neutral category. The same JJAS DMI criteria were used by Ajayamohan et al. (2008) to identify pIOD and nIOD events. Also, the SSTs in the EEIO are climatologically higher than in the WEIO, and a positive SST anomaly in EEIO means more convection over the EEIO than WEIO despite positive anomaly there, which we are not interested in this study. Thus, we impose the anomalous cooling criteria over the EEIO along with JJAS DMI criteria for associating a monsoon period into pIOD. The nIOD association is entirely based on the DMI.

The criteria we followed is:

a) If JJAS DMI $>0.5 \times S D$ and the EEIO show anomalous cooling, we would select that as positive IOD year.

b) If JJAS $D M I<-0.5 \times S D$, the year is marked as a negative IOD year.

The analysis is based on 35 years of the SST data from 1985 to 2019. Figure 1 shows the JJAS mean DMI index for the data analyzed. Among the years shown in Figure 1, those that did not satisfy the eastern box cooling criteria are 2007, 2015, and 2017 which were excluded from our analysis despite having a positive DMI index. 


\begin{tabular}{|l|l|}
\hline pIOD & nIOD \\
\hline $1991,1994,1997,2003,2012,2018$ & $1989,1990,1992,1996,1998,2001$, \\
2019. & $2005,2010,2013,2016$. \\
\hline
\end{tabular}

Table 1. pIOD and nIOD years.

\subsection{Difference in the mean structure across contrasting IOD years:}

First, we examine the difference in the mean SST, OLR, and winds between pIOD and nIOD years. Figure 2 shows the mean JJAS SST anomalies for pIOD, nIOD and the difference between pIOD and nIOD years, along with the regions mentioned earlier for calculating the DMI. The dipole in the SST anomaly is evident. Interestingly, the pIOD pattern (Fig. 2(a)) is marked by warm SST anomalies over a large region around and south of India. During nIOD years, the warm anomalies that are highest in the EEIO extend as an equatorial tongue up to about 60E (Fig. (2b)). The SST anomaly patterns simply do not reverse from pIOD to nIOD. The difference in the mean OLR anomalies along with mean 850 hpa winds are shown in Figure 3; comparing with Figure 2, the regions of higher SST's are the regions with negative OLR anomalies and vice versa, which signifies the role of SST's in generating/enhancing the convection over the Equatorial Oceans. Though at first glance, the wind pattern looks similar between pIOD and nIOD years, the difference between the two is evident (Fig. 3(c)) where the anomalous south-easterly winds from EEIO to central Equatorial Indian ocean during pIOD years can be seen.

232

\subsection{Differences in northward propagation across contrasting IOD years:}

To understand the differences in northward propagations across contrasting IOD years, we use daily OLR anomalies obtained by removing the daily climatology from the time series at each grid point. The OLR anomalies are then filtered using 25 - 80 days recursive Butterworth bandpass filter (hereafter referred to as ISO filtered) after removing the mean from the time series. The Butterworth bandpass filter was extensively used in past studies for extracting ISO signal (e.g., Krishnamurti (1982), Goswami et al. (1998), Misra et al. (2012), Misra et al. (2018)). The evolution composites of ISO filtered OLR anomalies are then constructed from individual cycles for nIOD and pIOD years (Table 1). The northward propagations are more apparent over the Indian Ocean sector (Yasunari (1979), Jiang et al. (2018)) and the strength of ISO convection is maximum between latitudes $5^{\circ} \mathrm{N}$ and $10^{\circ} \mathrm{N}$ (e.g., Jiang et al. (2004)). Thus, we construct composites in such a way that on lag 0 days, the minima of ISO filtered OLR (maxima of ISO convection) falls over the region $2.5^{\circ} \mathrm{N}-7.5^{\circ} \mathrm{N}$ and $70^{\circ} \mathrm{E}-95^{\circ} \mathrm{E}$ (centred at $\left.5^{\circ} N\right)$.

Figure 4 shows the evolution composite of ISO filtered OLR anomaly for nIOD years. The convection initiates at lag 12 days (Fig. 4(b)) close to $60^{\circ} \mathrm{E}$, along the equator. The convection then strengthens moving eastward, and, by lag 6 days, strong convection can be seen over central and East equatorial Indian ocean (between $80^{\circ} \mathrm{E}$ and $90^{\circ} \mathrm{E}$ longitudes) along the equator (Fig 4(d)). The convection further intensifies, and by lag 3 days, the convection centre reaches $90^{\circ} \mathrm{E}$ (Fig 4(e)), subsequently propagating northward. The convection centre reaches peninsular India by lead 6 days (Fig. 4(h)), and central India by lead 9 days (Fig. 4(i)). Slight southward propagation (Fig. 4(f) to 4(h)) off Sumatra is also seen, as pointed out in Lawrence and Webster (2002).

Figure 5 shows the evolution composite of ISO filtered OLR anomaly for pIOD years. We notice that the convection initiates at lag 12 days (Fig. 5(b)) again over WEIO but slightly to the west of $60^{\circ} \mathrm{E}$ and slightly 
to the north of the equator. By lag 9 days, we see an elongated region of moderate convection from $60^{\circ} \mathrm{E}$ to the southern tip of India (Fig. 5(c)). The convection further intensifies, moving east. By lag 3 days, intense convection can be seen just to the south of India (Fig. 5(e)), and the convection moves further eastward before weakening by lead 6 days (Fig. 5(h)). Weak northward propagation from lag 0 days to lead 9 days is evident (Fig. 5(f) to 5(i)). One more notable difference between the pIOD and nIOD years evolution composites is that during pIOD years, much of the strong convection prefers to stay north of the equator (Fig. 5(c) to 5(f)). During nIOD years, the convection moves along the equator (Fig. 4(c) to 4(f)). Comparing Figures 4 and 5 (f to i), it is evident that northward propagations are weaker during pIOD years, as pointed out in Ajayamohan et al. (2008). To confirm this observed weakening of northward propagations (Fig. 4 and Fig. 5) during pIOD years, we examined the individual evolution cycles from which the composites (Fig. 4 and Fig. 5) are constructed for nIOD and pIOD years. The following algorithm was used to count the northward propagating events.

\section{Algorithm:}

Step 1: The day when area-averaged ISO filtered OLR anomaly is minimum over the region $2.5^{\circ} \mathrm{N}-$ 7.5 $\mathrm{N}$ and $70^{\circ} \mathrm{E}-95^{\circ} \mathrm{E}$ is marked as day 0 . This condition can be expressed as follows: if $(O L R)_{n-1}>(O L R)_{n}<(O L R)_{n+1}$ then the $\mathrm{n}^{\text {th }}$ day is taken as day 0 for the cycle. Step 2: Check if the same condition in step 1 was met over the region $17.5^{\circ} \mathrm{N}-22.5^{\circ} \mathrm{N}$ and $70^{\circ} \mathrm{E}-95^{\circ}$ $E$ within 10 - 20 day's period from day 0 marked in step 1 . (Note that the region chosen in this step is north of the region selected in step 1)

Step 3: If the condition in step 2 associated with step 1 is satisfied, we count the event as a northward propagating event.

Using the above algorithm, we found that among 42 events across 10 nIOD years, 34 events (81\%)

276

277

278

279

280

281

282

283

284

285

286

287

288

289

290

291

292 propagated northward, while among 25 events across 7 pIOD years, only 7 (28\%) propagated northward. The reduction in the number of northward propagating events during nIOD years from this algorithm against the $95 \%$ significance shown in the composite plot (Fig. 4) could be because of the longitudinal extent we selected in step 2 of the algorithm for calculating the average ISO filtered OLR anomaly. Sometimes the propagation characteristics are such that northward propagation can be seen in the Arabian Sea and with no propagation in the Bay of Bengal and vice versa. The OLR minima criteria (step 2) is not satisfied sometimes in these kinds of events. Thus, the algorithm described above does not pick those propagations. The significance tests (Fig. 4 and Fig. 5) are done at each grid point rather than working with the area-averaged as in the algorithm and, thus, are more robust. Nevertheless, application of the algorithm confirms that the northward propagations are more prominent during nIOD years and weak during pIOD years.

As already discussed, though there is some difference in the structure of convection across contrasting IOD years, we here concentrate on lag 0 and ask the question, "Why were northward propagations weaker during pIOD years?" To answer this question, we resort to the "moisture mode" framework.

\section{Moist Entropy and its budget:}

The moist static energy (MSE) was used in several studies in the past for understanding the MJO propagation (e.g., Maloney (2009), Kiranmayi and Maloney (2011), Adames and Wallace (2015)). In our analysis, we use moist entropy instead of MSE. The MSE is conserved by the parcel under the hydrostatic and moist 
adiabatic assumption, while the moist entropy is conserved by the parcel in a slow, moist/dry adiabatic process (Raymond et al. (2009), Jiang et al. (2018)).

The moist entropy following Raymond et al. (2009) is given by,

$$
S=T_{R}\left(C_{p_{D}}+r_{v} C_{p v}\right) \ln \left(\frac{T}{T_{R}}\right)-R_{D} T_{R} \ln \left(\frac{P_{D}}{P_{R}}\right)-r_{v} R_{v} T_{R} \ln \left(\frac{p_{v}}{e_{S F}}\right)+L_{v} r_{v}^{----(1)}
$$

Where, $C_{p D}, R_{D}, p_{D}$ are specific heat, gas constant and pressure respectively of dry air, $C_{p v}, R_{v}, p_{v}$ are specific heat, gas constant and vapor pressure respectively of water vapor, $T$ is the temperature of the air in Kelvin, $T_{R}$ is the reference temperature, which is $273.15 \mathrm{k}, r_{v}=\frac{q}{1-q}$ is the water vapor mixing ratio (q being specific humidity), $L_{v}$ is the latent heat of vaporization taken as $2 \cdot 5 \times 10^{6} \mathrm{~J} / \mathrm{kg}$. The specific humidity is not directly available from reanalysis-2 data set; thus, it was constructed from temperature (T) and relative humidity (RH) following Bolton (1980), the saturation vapor pressure (Bolton (1980)) is given by,

$$
e_{s}=6.11 \exp \left(\frac{17 \cdot 67 T}{T+243.5}\right)
$$

Where $\mathrm{T}$ - Temperature of air in degrees Celsius. Once the saturation vapor pressure $\left(\mathrm{e}_{\mathrm{s}}\right)$ is obtained, the specific humidity (q) is constructed using,

$$
q=0.622 \frac{p_{v}}{p_{t}-p_{v}}
$$

Where $p_{v}$ is the vapor pressure given by $p_{v}=R H \times e_{s}$.

According to Bolton (1980), the Equation (2) fits with an error of $0.1 \%$ for temperatures in the range of $-30^{\circ} \mathrm{C}$ to $35^{\circ} \mathrm{C}$. Nevertheless, we checked for the accuracy of this constructed specific humidity comparing with reanalysis-1 specific humidity data available. We found that the constructed values are in good agreement. The JJAS climatology of vertically integrated specific humidity between $1000 \mathrm{hpa}$ level and $500 \mathrm{hpa}$ level averaged over the region $10^{\circ} \mathrm{S}-30^{\circ} \mathrm{N}$ and $60^{\circ} \mathrm{E}-120^{\circ} \mathrm{E}$ has root mean square error of $2.49 \mathrm{kgm}^{-2} / \mathrm{day}(6 \%$ of mean areaaveraged specific humidity over the same region in reanalysis data). Having obtained all the data available for the construction of entropy from Equation (1). We can write the entropy budget as:

$$
\frac{\partial s}{\partial t}=-v \cdot \nabla s-\omega \frac{\partial s}{\partial p}+f+q
$$

Where the first term $(-\bar{v} \cdot \nabla s)$ on RHS of Equation (4) represents the horizontal advection, the second fluxes and radiative fluxes, respectively.

Since we are interested in intraseasonal oscillations of timescales 25 - 80 days (northward propagations), we integrate (mass-weighted) the above Equation from $1000 \mathrm{hpa}$ level to $200 \mathrm{hpa}$ level and apply ISO filter (Maloney (2009)) giving:

$$
\left[\frac{\partial s}{\partial t}\right]_{I S O}=[-\bar{v} \cdot \nabla s]_{I s o}-\left[\omega \frac{\partial S}{\partial p}\right]_{I S O}+\mathrm{F}_{I S O}+Q_{I S O}^{---(5)}
$$

Where the terms within square bracket imply the vertical integration given by:

$$
[a]=\int_{1000}^{200} a \frac{d p}{g}
$$

We show the spatial relationship between the convection and the moist entropy before looking at the entropy budget. The ISO filtered OLR, and ISO filtered moist entropy anomalies corresponding to lag 0 days (Fig. 
327 4) are shown in Figure 6 for nIOD years. The OLR and moist entropy (Fig. 6) anomalies are out of phase at lag 328 0, and in fact, they are out phase at all the time. This relationship holds good even for pIOD years. Since OLR is 329 used here as a proxy for rainfall, the moist entropy and rainfall will be in phase as discussed in Jiang et al. (2018).

330 The latitude-time plot of ISO filtered OLR, and moist entropy averaged across the longitudes $70^{\circ} \mathrm{E}-95^{\circ} \mathrm{E}$ is 331 shown in Figure 7. The ISO filtered moist entropy also propagates northward like the OLR, and the out of phase relationship between OLR and entropy is well demonstrated (Fig. 7).

Figure 8 shows terms in Equation (5) when convection is centred at $5^{\circ} \mathrm{N}$ (lag 0 in Fig. 4) for nIOD years. The shortwave radiation and the longwave radiation data were available only between 1985 to 2009 in OAFlux data. The ISO filtered shortwave radiation contributes very little to the budget; thus, the ISO filtered shortwave radiation was omitted in the budget equation. It adds up to the residue term, which is very small even after omitting the shortwave radiation (Fig. 10). Each term's average values averaged over the region $10^{\circ} \mathrm{N}-20^{\circ} \mathrm{N}, 70^{\circ} \mathrm{E}-95^{\circ}$ $E$ (to the north of convection centre) are printed on each panel's top. Only the dominant terms are shown in Figure 8. The tendency term $\left(\left[\frac{\partial s}{\partial t}\right]_{I S o}\right.$, Fig. $\left.8(\mathrm{a})\right)$ to the north of the convection centre is majorly controlled by the 340 horizontal advection $\left([-\bar{v} \cdot \nabla s]_{I s o}\right.$, Fig. 8(b)), vertical advection $\left(\left[-\omega \frac{\partial S}{\partial p}\right]_{I S O}\right.$, Fig. 8(c) $)$ and the surface fluxes 341 ([F $]_{I s o}$, Fig. 8(d)). The contributions from the radiative fluxes are small (Fig. 10(a)). While the horizontal 342 advection tends to increase the entropy to the north of the convection centre, the other two terms tend to decrease it. The vertical advection terms peaks over the topographic features like western ghats and Myanmar. During pIOD years, in the budget of Equation (5), the tendency term $\left(\left[\frac{\partial s}{\partial t}\right]_{I S o}\right.$, Fig. 9(a)) to the north of the convection centre decreases considerably in comparison with nIOD years (Fig. 8(a)). The horizontal advection $\left([-\bar{v} \cdot \nabla s]_{I s o}\right)$ which is the major contributor to the tendency term during nIOD years is also significantly reduced during pIOD years (Fig. 9(b)). Even though magnitudes of vertical advection (Fig. 9(d)) and surface fluxes (Fig. 9(c)) reduced considerably, the tendency during pIOD is decreased majorly due to reduction in horizontal advection. To understand the reason for this reduction in the horizontal advection term, we split Equation (5) into zonal and meridional components as,

$$
-[\bar{v} \cdot \nabla s]_{I S o}=-\left[u \frac{\partial s}{\partial x}\right]_{I S o}-\left[v \frac{\partial s}{\partial y}\right]_{I S o}---(7)
$$

Where the first a second terms on RHS represents zonal advection and meridional advection, respectively. The major contribution to the horizontal advection term comes from the zonal advection $\left(-\left[u \frac{\partial s}{\partial x}\right]_{I S O}\right)$ term and there is also a considerable contribution from the meridional advection term $\left(-\left[v \frac{\partial s}{\partial y}\right]_{I S o}\right)$ in nIOD years (Fig. 11(a)). The contribution from meridional advection during pIOD years (Fig. 11(b)) is negligible. Thus, the major difference in horizontal advection between the contrasting IOD years seems to be due to the drastic reduction in the contribution of the meridional advection term.

The smaller budget terms at lag 0 days during pIOD years could result from the phase relationship difference across contrasting IOD years. To investigate this, we examined the phase relationship between the horizontal advection $\left(-[\bar{v} \cdot \nabla s]_{I S o}\right)$ term and the OLR/rainfall, by constructing a composite lag-phase diagram of horizontal advection and its components along with the OLR (all ISO filtered) averaged over the region $10^{\circ} \mathrm{N}-$ 
corresponds to the day when the OLR minima occur at $5^{\circ} \mathrm{N}$. The amplitudes of oscillation of all the variables are much smaller during pIOD years (Fig. 12(b)) in comparison with nIOD years (Fig. 12(a)) at all lag/lead times. The maxima in the horizontal advection for nIOD years coincidentally occurs close to lag 0 days, and for pIOD years the maxima occur close to lead 2 days. Thus, the moisture in the atmosphere to the north of the convection centre is enhanced by the horizontal advection during both nIOD and pIOD years. Nevertheless, during pIOD years the amplitudes were smaller, and both the zonal and meridional advection weakens with the contribution from the latter being almost zero. Also, during nIOD years, the minima (maxima) in OLR (rainfall) over the region $10^{\circ} \mathrm{N}-20^{\circ} \mathrm{N}, 70^{\circ} \mathrm{E}-95^{\circ} \mathrm{E}$ occurs close to lag 10 days (Fig. 12(a)) which is consistent with $1 \%$ day speed of propagation as observed in previous studies (e.g., Yasunari (1979), Krishnamurti (1982), Jiang et al. (2004)).

\subsection{Vertical structure of Horizontal advection:}

To understand the smaller amplitude of horizontal advection during pIOD years, the horizontal advection's vertical structure across the contrasting IOD years averaged over the region $10^{\circ} \mathrm{N}-20^{\circ} \mathrm{N}, 70^{\circ} \mathrm{E}-95^{\circ}$ $E$ (region to the north of convection centre at lag 0 days) is examined at various lag/lead times (Fig. 13). During nIOD years (Fig. 13(a)), there exist two local maxima/minima in horizontal advection $(-\bar{v} \cdot \nabla s)$ one in the lower troposphere between $1000 \mathrm{hpa}$ and $850 \mathrm{hpa}$ levels, and the other in the middle troposphere between $600 \mathrm{hpa}$ and 400 hpa levels. The magnitude of the lower troposphere maximum is larger $\left(>0.0075 \frac{\mathrm{w}}{\mathrm{kg}}\right)$ than that of the magnitude of maximum in the middle troposphere (just above $0.0025 \frac{w}{\mathrm{~kg}}$ ). While the lower troposphere maximum/minimum can be seen in pIOD years (but smaller magnitudes), the middle troposphere undergoes remarkable change (Fig. 13(b)). Though the secondary maximum is seen in the middle troposphere during pIOD years, the magnitude of the same (close to $0.0005 \frac{\mathrm{w}}{\mathrm{kg}}$ ) is much smaller than the same for nIOD years.

To understand what causes this change, we examined the contribution of zonal $\left(-u \frac{\partial s}{\partial x}\right)$ and meridional

$\left(-v \frac{\partial s}{\partial y}\right)$ advection terms to the vertical structure of horizontal advection. In Figure 14, vertical structures of zonal and meridional advection leading to Figure 13 are separated and plotted. While during both pIOD and nIOD years, the meridional advection helps in moistening the boundary layer and lower troposphere up to $800 \mathrm{hpa}$ (Fig. 14(c) and 14(d)). The vertically integrated value on day 0 remains small during pIOD events (Fig. 11 and 12) because of a slightly smaller magnitude of meridional advection along with slight negative advection at middle and higher troposphere (Fig. 14(d)). The major difference, as seen in Figure 14 though, occurs in the zonal (Fig. 14 (a) and (b)) advection which helps to moisten the middle troposphere and a part of the lower troposphere close to $850 \mathrm{hpa}$ level. A strong moistening signal can be seen during nIOD years (Fig. 14(a)) with a primary maximum close to $850 \mathrm{hpa}$ level and secondary maximum close to $600 \mathrm{hpa}$, whereas the signal is weaker in pIOD years (Fig. 14(b)). Though the two maxima are still present, their magnitudes, especially the one at $850 \mathrm{hpa}$ level, is much smaller than nIOD years. Thus, despite the lower troposphere's moistening by meridional advection to the north of the convection centre during pIOD years, zonal advection's contribution is considerably smaller, leading to weaker entropy advection above 700 hpa level (Fig. 13(b)), to the north of convection centre.

The same conclusion can be obtained from the latitude - height structure of zonal and meridional advection at lag 0 days shown in Figure 15. The zonal advection in nIOD years helps in moistening the middle 

of the boundary layer and lower troposphere by meridional advection is present in both the contrasting IOD years, but the signal is stronger during nIOD years (Fig. 15(c)) than the during pIOD years (Fig. 15(d)). This structure leads to strong moistening of the lower and middle troposphere to the north of the convection centre during the nIOD year (Fig. 15(e)), while the moistening is weaker during pIOD years (Fig. 15(f)).

Having understood the relative roles of zonal and meridional advection in the structure of horizontal advection during nIOD and pIOD years, we can ask the question, "what are the processes that regulate the horizontal advection?" to answer this question, we can split the total zonal and meridional advection into respective components (Maloney (2009)) as,

$$
\begin{aligned}
& {\left[u \frac{\partial s}{\partial x}\right]_{I S o} \approx\left[\bar{u} \frac{\partial s^{\prime}}{\partial x}\right]_{I S O}+\left[u^{\prime} \frac{\partial \bar{s}}{\partial x}\right]_{I S o}+\left[u^{\prime} \frac{\partial s^{\prime}}{\partial x}\right]_{I S o}--(8)} \\
& {\left[v \frac{\partial s}{\partial y}\right]_{I S o} \approx\left[\bar{v} \frac{\partial s^{\prime}}{\partial y}\right]_{I S o}+\left[v^{\prime} \frac{\partial \bar{s}}{\partial y}\right]_{I S o}+\left[v^{\prime} \frac{\partial s^{\prime}}{\partial y}\right]_{I S o}---(9)}
\end{aligned}
$$
represent a deviation from the mean. These perturbations contain both the high frequency (less than 25 days) and low frequency ( $80-25$ days) perturbations. Later in section 4.2 we show that the contribution to the budget from the high frequency terms is negligible.

The zonal advection budget (Equation (8)) for nIOD and pIOD events over the region $10^{\circ} \mathrm{N}-20^{\circ} \mathrm{N}, 70^{\circ}$ $E-95^{\circ} E$ at various lag/lead times are shown in Figure 16. The major contribution to the zonal advection during both nIOD and pIOD years comes from the advection of mean entropy by perturbed zonal wind $\left(u^{\prime} \frac{\partial \bar{s}}{\partial x}\right)$ term, but the magnitude of $u^{\prime} \frac{\partial \bar{s}}{\partial x}$ term is reduced by a factor of three during pIOD years (Fig. 16(a) and 16(b)). Similarly, the meridional advection budget was performed, and it was found that all the three terms on the RHS of Equation (9) contribute equally to the budget (not shown here). We have already discussed the dominance of the zonal advection term in dictating horizontal advection's vertical structure and the low-level moisture being enhanced by meridional advection term even during pIOD years (albeit smaller magnitudes). Also, it is evident (Fig. 16) that the term $u^{\prime} \frac{\partial \bar{s}}{\partial x}$ solely explains the difference in zonal advection during contrasting IOD years, so discussion of meridional advection budget is omitted here.

Thus, the major difference in the zonal advection $\left(-\left[u \frac{\partial s}{\partial x}\right]_{I S O}\right)$ term during contrasting IOD years should either come from the different mean entropy gradients $\left(\frac{\partial \bar{s}}{\partial x}\right)$ or the perturbation of zonal velocities $\left(u^{\prime}\right)$ across contrasting IOD years (Since $u^{\prime} \frac{\partial \bar{s}}{\partial x}$ term is the prime contributor to zonal advection budget). To understand which of these two terms is responsible for the smaller amplitude of zonal advection during pIOD years, we have examined the perturbed velocity vectors at $850 \mathrm{hpa}$ level corresponding to lag 0 days along with the JJAS mean 
years are drawn (Fig. 17). It is evident from Figure 17 that the mean structure of entropy $(\bar{s})$ over the Indian region

435 does not differ much across contrasting IOD years, the major difference between the two is the presence of strong easterly wind perturbations (u') during nIOD years between latitudes $10^{\circ} \mathrm{N}-20^{\circ} \mathrm{N}$ at lag 0 days (Fig. $17(\mathrm{a})$ ), those perturbations are much weaker during pIOD years (Fig. 17(b)). These weaker wind perturbations result in very weak zonal advection to the north of the convection centre (Fig. 14(b), 15(b)) during pIOD years in comparison with nIOD years (Fig. 14(a), 15(a)), leading to weaker tendencies of entropy (moisture build up), and thus weaker northward propagations during pIOD years. can further approximate the perturbation term as the sum of high frequency and low-frequency terms as,

$$
u^{\prime} \approx u_{l f}+u_{h f}---(10)
$$

Where $l f$ - low-frequency mode corresponding to the periodicities of $25-80$ days, $h f$ - high-frequency mode corresponding to $10-25$ days. These two timescales are considered dominant periodicities in ISO, e.g., Yasunari (1979), Kamrakar et al. (2017). Thus, the term $u^{\prime} \frac{\partial \bar{s}}{\partial x}$ can be written as:

$$
u^{\prime} \frac{\partial \bar{s}}{\partial x} \approx u_{l f} \frac{\partial \bar{s}}{\partial x}+u_{h f} \frac{\partial \bar{s}}{\partial x}---(11)
$$

The budget pertaining to Equation (11) is shown in Figure 18. The dominance of low-frequency zonal wind can be seen. Thus, in conclusion, the major difference in the zonal advection between nIOD and pIOD events that inhibits the northward propagation during pIOD events is the weaker amplitudes of zonal wind perturbations at 25 - 80 days timescales. In fact, the low-frequency wind at $850 \mathrm{hpa}$ level on lag 0 days looks almost the same as shown in Fig. 17(a) for nIOD years (not shown here).

\section{Possible Mechanism for Weaker Propagations during pIOD years.}

Having understood the reason for weaker northward propagations in pIOD years, we propose the following mechanism for weakening: Referring to Figure 17, we realize that weaker zonal wind perturbations, on an average during pIOD years, are responsible for weaker propagations. The perturbed wind structure for nIOD (Fig. 17(a)) appears like a Gill - type response (Gill (1980)) to symmetric convective heating about the equator, with two cyclonic vorticities (Rossby wave lobes) to the northwest and the southwest of convection centre/heating, easterly winds to east and north and westerly winds to the west of convection centre. But during pIOD years (Fig. 17(b)), weak vortices can be seen with weak easterly wind perturbations to the north of the convective centre. This difference in the equatorial wave response across contrasting IOD years results from the difference in the convective heating structure during ISO events. Figure 19 shows the structure of convective heating at lag 5 days. For nIOD years (Fig. 19(a)), the positive moist entropy anomalies (which implies convective heating) are present on either side of the equator (though not exactly symmetric), and are confined mainly to EEIO, Sumatra and Borneo. During pIOD years (Fig.19(b)), strong convective heating is primarily confined to the north of the equator. Also, the extent of positive anomalous entropy reaches much further west and north into warm waters (Fig. 2(a)) of WEIO and SEAS with weaker anomalies to the east of Sumatra. This difference in convective heating structure generates different equatorial wave responses across contrasting IOD years.

The difference in convective heating structure (Fig. 19) between nIOD and pIOD years can be explained 
on either side of the equator (Fig. 2(b)); this strengthens the positive SST gradient between WEIO and EEIO on

473 either side of the equator. This positive SST gradient helps in destabilizing the boundary layer to the east of the ISO convection centre on either side of the equator through surface convergence (Linzden (1987)), leading to a near symmetric structure of convection about the equator as convection moves eastward initially. During pIOD years, the negative SST anomalies are confined mainly to the south of the equator (Fig. 2(a)), while positive anomalies are located to the north of the equator. Thus, strengthening the positive SST gradient to the north of the equator and flattening the SST gradient to the south of the equator. This SST structure makes the atmosphere to the north of the equator to be more unstable and confines the strong convection to the north of the equator. Also, the warmer waters over SEAS during pIOD years (Fig. 2(a)) enhance local convective heating (Fig. 19(b)). Figure 20 shows the sequence of events we propose to be responsible for weak (strong) northward propagations during pIOD (nIOD) years.

Some studies in the past (e.g., Wang and Xie (1997), Kemball - Cook and Wang (2001), Jiang et al. (2018)) observed the strength of the Rossby wave lobe (vortex) in the northern hemisphere to be stronger than the one in the southern hemisphere because of destabilizing caused by the easterly wind shear (Wang and Xie (1997)). We see that the strength of the southern hemisphere lobe (Fig. 17(a)) on day 0 to be slightly stronger than the one in the northern hemisphere mainly because of warmer waters and slightly enhanced specific humidity in SEIO during nIOD years leading to strong Rossby wave response in Southern hemisphere. In the following days, the lobe in the northern hemisphere gets stronger, and the one in the southern hemisphere gets weaker (not shown here).

\section{Summary and discussion:}

Northward propagations of intraseasonal oscillation are one of the dominant modes of tropical variability during the monsoon season and are associated with active and break spells of the Indian summer monsoon (Yasunari (1979) Sikka and Gadgil (1980)). IOD, an ocean-atmospheric interaction, is considered as an internal mode of variability in the Indian Ocean (Saji et al. (1999)). In this study, we address the question: "How the northward propagations get modulated by IOD?" and "What are the processes responsible for that modulation?". Using NOAA OLR data, we showed that during nIOD years, strong northward propagations of ISO filtered OLR anomalies can be seen from the equatorial region to $20^{\circ} \mathrm{N}$ (Fig. 4), but during pIOD years the northward propagations are much weaker with the OLR anomalies from the equator barely reaching past $10^{\circ} \mathrm{N}$ (Fig. 5). Recently using the moisture mode framework, Jiang et al. (2018) highlighted the role of mean moisture pattern for northward propagation of ISO. Thus, to understand north ward propagations' weakening during pIOD years, we conducted a moisture entropy budget in this study.

Results suggest that a reduction in the horizontal advection of entropy (moisture) during ISO events is responsible for the weakening of northward propagations. Further analysis revealed that the mean structure of entropy remained more or less similar across contrasting IOD years, and weaker horizontal advection during pIOD years results from weaker zonal wind perturbations at intraseasonal timescales. During nIOD years, we observed strong zonal wind perturbations to the north of the ISO convection centre (Fig. 17(a))), but during pIOD years these zonal wind perturbations are weak (Fig. 17(b)). These weaker zonal wind perturbations result from a change 
512 over the EEIO and adjoining maritime continent. During pIOD years, intense convective heating is mainly

513 confined to the north of the equator and, the extent of convective heating reaches as far as WEIO and SEAS. This

514 convective heating structure leads to the different response of the equatorial waves. Thus, the equatorial wave

515 dynamics play a crucial role in enhancing (weakening) the northward propagations during nIOD (pIOD) years. In

516 similar lines, a mechanism is proposed for explaining weaker northward propagations during pIOD years.

517 The ISMR is influenced by the relative strengths of ElNino/ENSO and IOD (Ashok et al. (2001), Ashok

518 et al. (2004), Gadgil et al. (2004)). The pIOD event enhances the ISMR in the absence of the ElNino event.

519 However, when they co-occur, the ISMR is dictated by the relative strengths of the IOD and ENSO events (Ashok

520 et al. (2001)). For example, 2019 can be considered as a year with weak Elnino - strong pIOD and ISMR was

521 109\%, above normal. More interestingly, in the June of 2019, the rainfall over the Indian subcontinent was $67 \%$

522 of the normal, but the JJAS mean rainfall ended 9\% above the normal. This 33\% deficit during June 2019 was a

523 response to SST anomaly outside the Indian ocean (ElNino), while the unusually high September rainfall (152\%)

524 was due to the pIOD event (Gadgil et. al (2019), Ratna et al. (2021)). Significant anomalies in ISMR are associated

525 with the EQUINOO and an index that is a linear combination of ENSO and EQUINOO explains the ISMR

526 anomalies in all seasons (Gadgil et al. (2004)). The details of the roles of ENSO and EQUINOO in intraseasonal

527 rainfall variations was also documented in Francis and Gadgil (2009).

$528 \quad$ Nevertheless, "How the weakening of the northward propagations from the equator results in the 529 enhanced ISMR?" needs further studies and investigation. We would like to answer this question by referring to

530 Sikka and Gadgil (1980). They observed that the convection in the equatorial region and monsoon zone (north of

$53115^{\circ} \mathrm{N}$ ) exhibits see-saw behaviour, and lesser convection over the equatorial region was considered favourable 532 for ISMR. Thus, during pIOD years when the equatorial region $\left(80^{\circ} \mathrm{E}-110^{\circ} \mathrm{E}\right)$ is not favourable for convection, 533 the monsoon zone should be having excess rainfall and vice versa. Figure 21 shows the JJAS anomaly of vertical 534 pressure velocity, and the anomalous meridional circulation for pIOD and nIOD years (Table 1) strengthens our 535 argument. Anomalous ascent can be seen between latitudes $5^{\circ} \mathrm{N}$ and $15^{\circ} \mathrm{N}$ over the Indian region during pIOD 536 years (Fig. 21(a)), and this ascending air crosses the equator and sinks just to the south of the equator. This 537 anomalous ascent over India enhances ISMR during pIOD years. During the nIOD years, there are two regions of 538 weak anomalous ascent just to the north and south of the equator with weak descent over the Indian region (Fig. $53921(\mathrm{~b}))$, resulting in a reduction in the rainfall over the core monsoon region.

540

541 Acknowledgements. PNV acknowledges partial financial support from J C Bose National Fellowship, SERB,

542 DST, Govt. India, and BoBBLE program funded by Ministry of Earth Sciences, Govt. of India under its Monsoon

543 Mission program. AK acknowledges financial support from MHRD Govt. India, Grantham fellowship. We 544 thank NOAA for daily gridded OLR data, daily gridded SST data, NCEP for reanalysis data and OAFlux for daily 545 gridded heat flux data.

\section{References:}

548 Adames. Á. F., and D. Kim, 2016: The MJO as a Dispersive, Convectively Coupled Moisture Wave: Theory and 549 Observations. J. Atmos. Sci., 73, 913-941, https://doi.org/10.1175/JAS-D-15-0170.1.

550 Adames, Á. F., and J. M. Wallace, 2015: Three-Dimensional Structure and Evolution of the Moisture Field in the MJO. J. Atmos. Sci., 72, 3733-3754, https://doi.org/10.1175/JAS-D-15-0003.1. 
Adames, J. M. Wallace, and J. M. Monteiro, 2016: Seasonality of the structure and propagation characteristics of

553 the MJO. J. Atmos. Sci., 73, 3511-3526, https://doi.org/10.1175/JAS-D-15-0232.1.

554 Ajayamohan, R. S., Rao, S. A. \& Yamagata, T., 2008. Influence of Indian Ocean Dipole on Poleward Propagation

555 of Boreal Summer Intraseasonal Oscillations. J. Climate, 21, 5437- 5454,

556 https://doi.org/10.1175/2008JCLI1758.1.

557 Ashok, K., Z. Guan, and T. Yamagata, 2001: Impact of the Indian Ocean dipole on the relationship between the

558 Indian monsoon rainfall and ENSO. Geophys. Res. Lett., 28, 4499-

559 4502, https://doi.org/10.1029/2001GL013294

560 Ashok, K., Guan, Z., Saji, N. H., and Yamagata, T., 2004a: Individual and combined influences of the ENSO

561 and Indian Ocean Dipole on the Indian summer monsoon, J. Climate, 17, 3141-3155,

562 https://doi.org/10.1175/1520-0442(2004)017<3141:IACIOE>2.0.CO;2

563 Bhat, G., S. Gadgil, S. Kumar, P. V. Hareesh, Kalsi, S. R., Madhusoodanan, P. Murty, V. SN Prasada Rao, C. V.

564 K. Babu, and V. Ramesh Rao, 2001: BOBMEX: The Bay of Bengal monsoon experiment. Bull Amer Meteor

565 Soc., 82, 2217 - 2243.

566 Bolton, D.,1980: The Computation of Equivalent Potential Temperature. Monthly Weather Review, 108, 1046-

5671053.

568 Fu, X., B. Wang, T. Li, and J. P. McCreary (2003), Coupling between northward-propagating, intraseasonal 569 oscillations and surface temperature in the Indian Ocean, J. Atmos. Sci.,60, 1733-1753.

570 Francis P A and Gadgil Sulochana, 2010: Towards understanding the unusual Indian monsoon in 2009; J. Earth 571 Syst. Sci. 119(4), 397-415.

572 Gadgil, S., Srinivasan, J., Nanjundiah, R. S., Kumar, K. K., Munot, A. A., \& Kumar, K. R., On forecasting the 573 Indian summer monsoon: the intriguing season of 2002, Curr. Sci., 2002, 83, 394-403.

574 Gadgil, S., P. N. Vinayachandran, P. A. Francis, and S. Gadgil, 2004: Extremes of the Indian summer monsoon

575 rainfall, ENSO and equatorial Indian Ocean oscillation. Geophys. Res. Lett., 31,

576 L12213, https://doi.org/10.1029/2004GL019733.

577 Gadgil, S., Francis, P.A. and Vinayachandran, P.N., 2019. Summer monsoon of 2019: understanding the

578 performance so far and speculating about the rest of the season. Current Science, 117(5), p.783.

579 Gill, A. E., 1980: Some simple solutions for heat-induced tropical circulation. Quart. J. Roy. Meteor. Soc., 106, $580 \quad 447-462$.

581 Goswami, B. N., D. Sengupta, and G. S. Kumar, 1998: Intraseasonal oscillations and interannual variability of

582 surface winds over the Indian monsoon region. J. Earth Syst. Sci., 107, 45-

583 64, https://doi.org/10.1007/BF02842260.

584 Huang, Boyin; Liu, Chunying; Banzon, Viva F.; Freeman, Eric; Graham, Garrett; Hankins, Bill; Smith, Thomas

585 M.; Zhang, Huai-Min. (2020): NOAA 0.25-degree Daily Optimum Interpolation Sea Surface Temperature

586 (OISST), Version 2.1 [SST anomaly]. NOAA National Center for Environmental Information.

587 Jiang. X, Li. T and B. Wang, 2004: Structures and mechanisms of the northward propagating boreal summer

588 intraseasonal oscillation. J. Climate, 17, 1022-1039, https://doi.org/10.1175/1520- 0442(2004)017, 1022 :

\section{SAMOTN.2.0.CO;2.}

590 Jiang, X. 2017: Key processes for the eastward propagation of the Madden-Julian Oscillation based on 591 multimodel simulations. J. Geophys. Res. Atmos., 122, 755-770, https://doi.org/10.1002/2016JD025955. 

seasonality of the Madden Julian oscillation. Journal of Climate, 31(11), 4215-4224. https://doi.org/10.1175/JCLI-D-17-0671.1.

595 Karmakar, N., Chakraborty, A., \& Nanjundiah, R. S. (2017). Space-Time Evolution of the Low- and High596 Frequency Intraseasonal Modes of the Indian Summer Monsoon. Monthly Weather Review, 145(2), 413-435. 597 https://doi.org/10.1175/MWR-D-16-0075.1.

598 Kemball-Cook, S., and B. Wang, 2001: Equatorial waves and air- sea interaction in the boreal summer 599 intraseasonal oscillation. J. Climate, 14, 2923-2942, https://doi.org/10.1175/1520$600 \quad$ 0442(2001)014<2923:EWAASI $>2.0 . \mathrm{CO} ; 2$.

601 Kiranmayi, L., and E. D. Maloney, 2011: Intraseasonal moist static energy budget in reanalysis data. J. Geophys.

602 Res., 116, D21117, https://doi.org/10.1029/2011JD016031.

603 Krishnamurti, T. N and Subramanyam, D 1982: The 30 - 50 days mode at 850 mb during MONEX. J.Atmos.sci, 604 39, 2088-2095.

605 Krishnamurti TN, Oosterhof DK, Mehta AV (1988) Air-sea interaction on the time scale of 30 to 50 days. J 606 Atmos Sci J5:1304.

607 Lawrence, D. M., and P. J. Webster, 2002: The boreal summer intraseasonal oscillation: Relationship between 608 northward and eastward movement of convection. J. Atmos. Sci., 59, 1593-1606, https://doi.org/10.1175/1520$609 \quad$ 0469(2002)059<1593:TBSIOR>2.0.CO;2 .

610 Liebmann B. and C.A. Smith, 1996: Description of a Complete (Interpolated) Outgoing Longwave Radiation 611 Dataset. Bulletin of the American Meteorological Society, 77, 1275-1277.

612 Lindzen, R. S., and S. Nigam, 1987: On the role of sea surface temperature gradients in forcing low-level winds 613 and convergence in the tropics. J. Atmos. Sci., 44, 2418-2436

614 Maloney, E. D., 2009: The moist static energy budget of a composite tropical intraseasonal oscillation in a climate 615 model. J. Climate, 22, 711-729, https://doi.org/10.1175/2008JCLI2542.1.

616 Misra, V., P. Pantina, S. C. Chan, and S. DiNapoli, 2012: A comparative study of the Indian summer monsoon 617 hydroclimate and its variations in three reanalyses. Climate Dyn., 39, 1149618 1168, https://doi.org/10.1007/s00382-012-1319-y.

619 Misra V, Mishra A, Bhardwaj A,2018: Simulation of the intraseasonal variations of the Indian Summer Monsoon 620 in a Regional Coupled Ocean-Atmosphere Model. J Clim, https://doi.org/10.1175/JCLI-D-17-0434.1

621 Raymond, D. J., and Z. Fuchs, 2009: Moisture modes and the Madden-Julian Oscillation. J. Climate, 22, 3031622 3046, https://doi.org/10.1175/2008JCLI2739.1.

623 Ratna, S. B., Cherchi, A., Osborn, T. J., Joshi, M., \& Uppara, U. (2021). The extreme positive Indian Ocean 624 Dipole of 2019 and associated Indian Summer Monsoon rainfall response. Geophysical Research Letters, 48, 625 e2020GL091497. https://doi.org/10.1029/2020GL091497.

626 Saji, N. H., Goswami, B. N., Vinayachandran, P. N., \& Yamagata, T. (1999). A dipole mode in the tropical Indian 627 ocean. Nature, 401, 360-363. https://doi.org/10.1038/43854.

628 Saji, N. H, and T. Yamagata, 2003a: Possible impacts of Indian Ocean Dipole mode events on global climate. 629 Climate Res., 25, 151-169. 
630 Sengupta, D., and M. Ravichandran, 2001: Oscillations of Bay of Bengal sea surface temperature during the 1998

631 summer monsoon. Geophys. Res. Lett., 28, 2033-2036.

632 Sengupta, D., B. N. Goswami, and B. Senan, 2001: Coherent intraseasonal oscillations of ocean and atmosphere

633 during the Asian summer monsoon. Geophys. Res. Lett., 28, 4127-4130.

634 Sikka, D. R., \& Gadgil, S (1980), On the maximum cloud zone and the ITCZ over Indian longitudes during the 635 southwest monsoon, Mon. Weather Rev., 108, 1840- 1853.

636 Sobel. A., and E. Maloney, 2012: An idealized semi-empirical framework for modeling the Madden-Julian 637 Oscillation. J. Atmos. Sci., 69, 1691-1705, https://doi.org/10.1175/JAS-D11-0118.1.

638 Sobel AH, Maloney ED, 2013: Moisture modes and the eastward propagation of the MJO. J Atmos Sci 70:187639 192. https ://doi.org/10.1175/JAS-D-12-0189.1

640 Vinayachandran, P. N., Francis, P. A., \& Rao, S. A. (2010). Indian Ocean dipole: Processes and impacts, Current 641 Trends in Science, 569-589.

642 Webster, P. J., 1983: Mechanisms of low-frequency variability: Surface hydrological effects. J. Atmos. Sci., 40, $6432110-2124$.

644 Webster, P. J., A. Moore, J. Loschnigg, and M. Leban (1999), Coupled ocean-atmosphere dynamics in the Indian 645 Ocean during 1997-98, Nature, 401, $356-360$.

646 Wang B, Xie X (1997) A model for the boreal summer intra-seasonal oscillation. J Atmos Sci 54:72-86.

647 Yu, L., X. Jin, and R. A. Weller, 2008: Multidecade Global Flux Datasets from the Objectively Analyzed Air-sea

648 Fluxes (OAFlux) Project: Latent and sensible heat fluxes, ocean evaporation, and related surface meteorological 649 variables. Woods Hole Oceanographic Institution, Woods Hole, MA, OAFlux Project Tech. Rep. OA-2008-01, 65064 pp.

651

652

653

654

655

656

657

658

659

660

661

662

663

664

665

666 
676

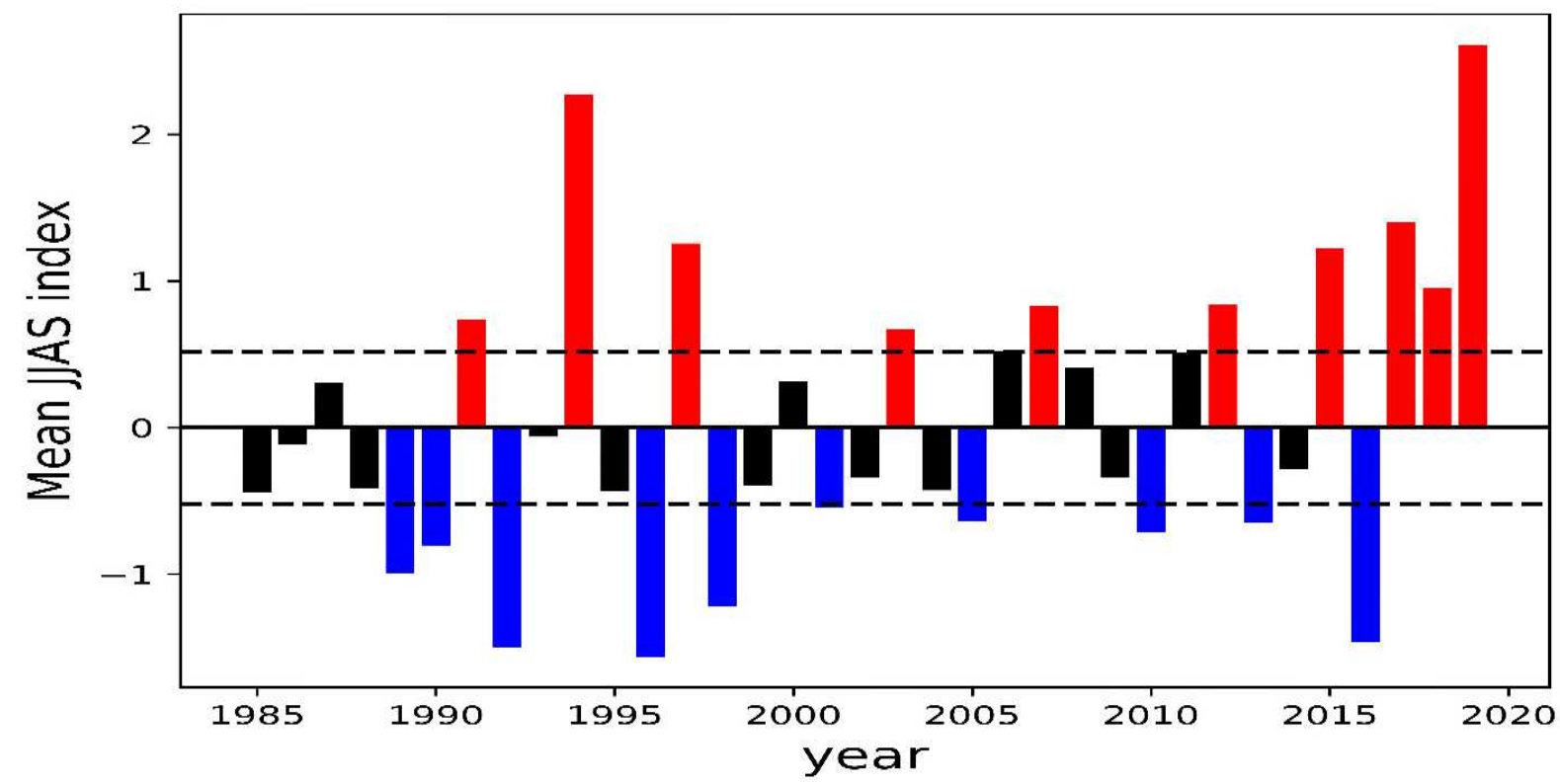

678

679

Fig. 1 The mean JJAS DMI from 1985 to 2019, years in which JJAS DMI crossed the $+0.5 \times$ SD values are marked in red, those years when the JJAS DMI values were less than $-0.5 \times \mathrm{SD}$ are marked in blue, and the rest 681 are in black. The dashed lines show +- 0.5S.D values.

682

683

684

685

686

687

688

689

690

691

692 


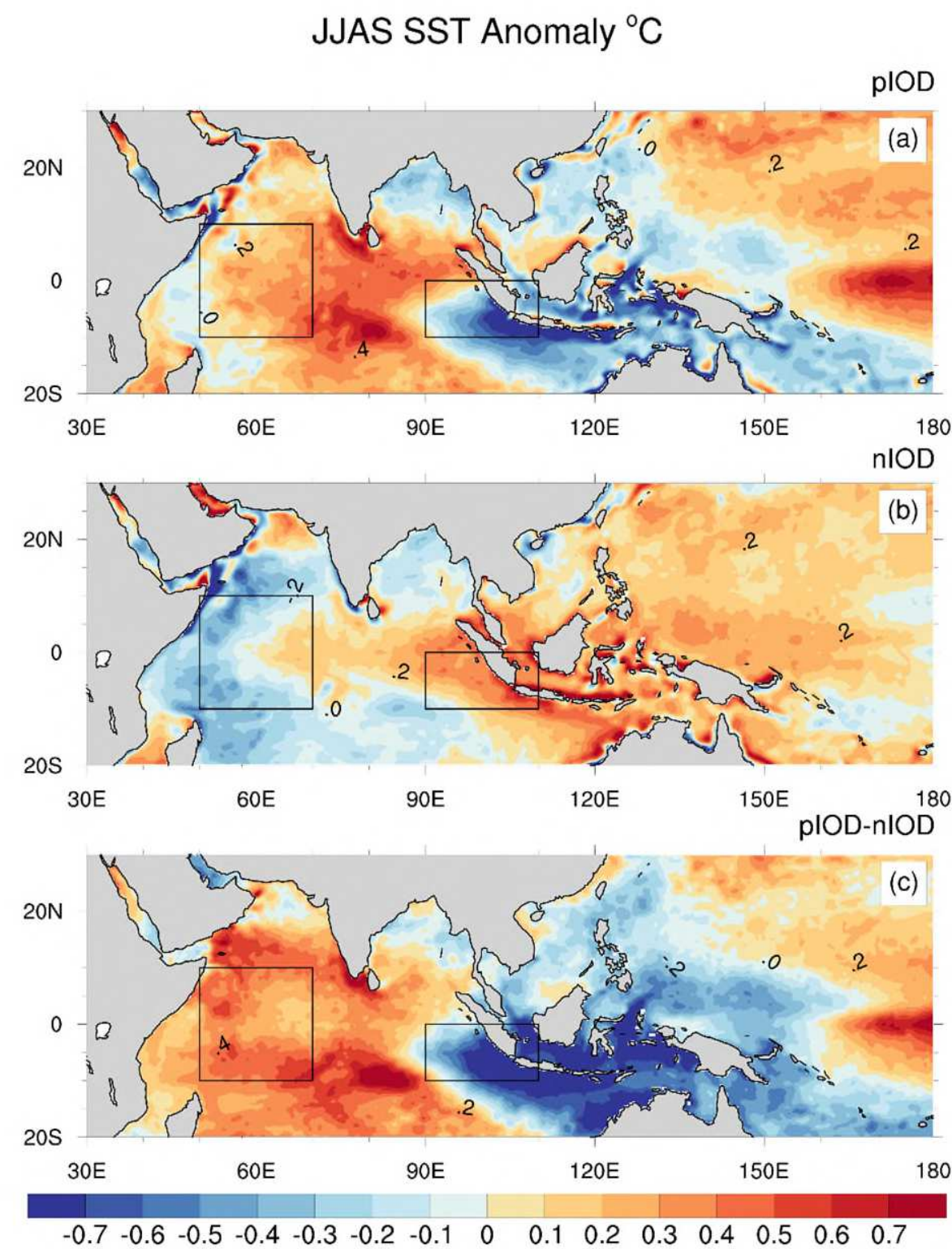

Fig. 2 The mean JJAS SST $\left({ }^{\circ} \mathrm{C}\right)$ anomalies for a) pIOD, b) nIOD and c) difference between pIOD and nIOD 


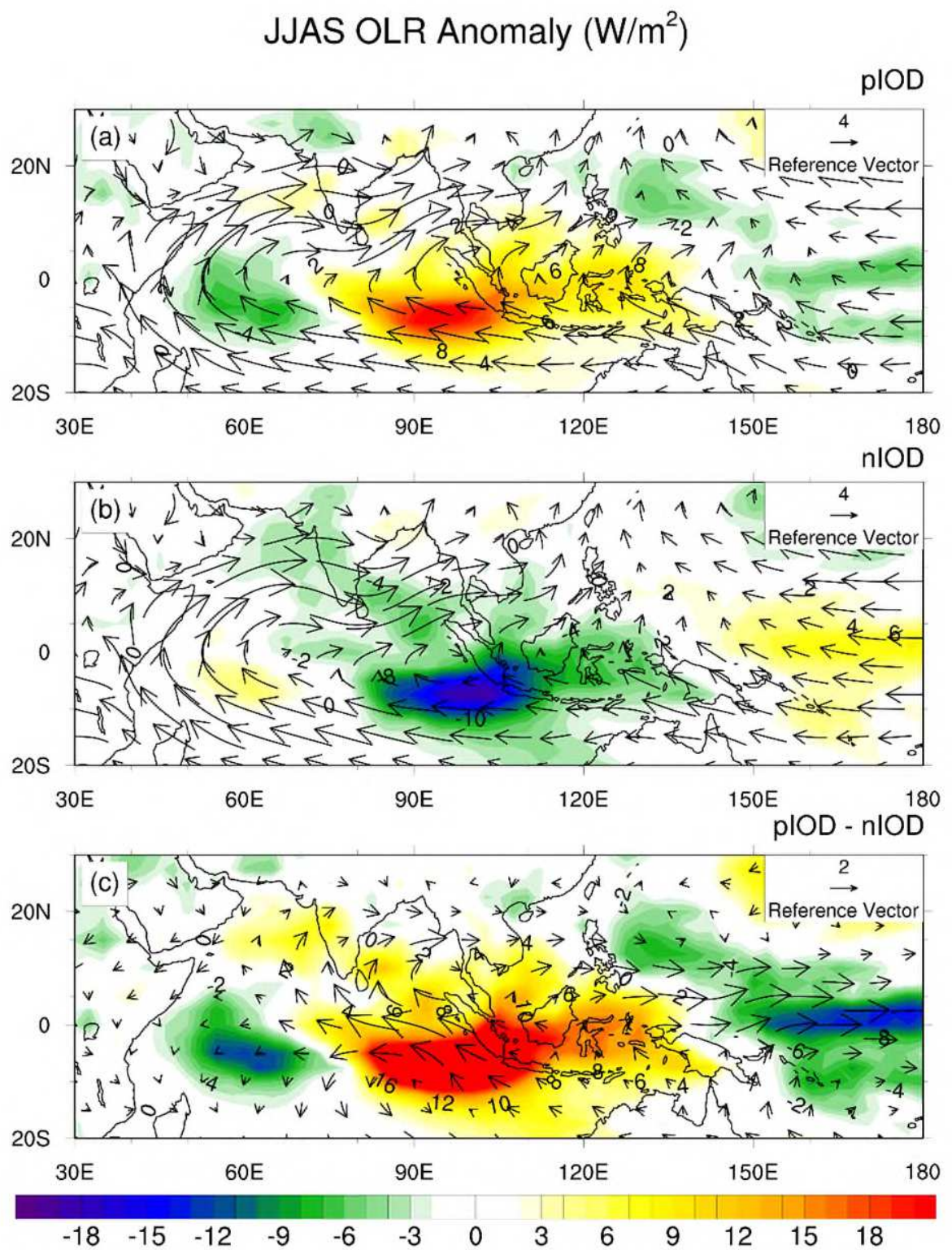

711 Fig. 3 The mean JJAS OLR (W/m²) anomalies and $850 \mathrm{hpa}$ wind vectors (m/s) for a) pIOD, b) nIOD and c)

712 difference between pIOD and nIOD years. The reference vectors are shown to the top right of each panel. 
Composite of ISO filtered OLR anomaly for pIOD years
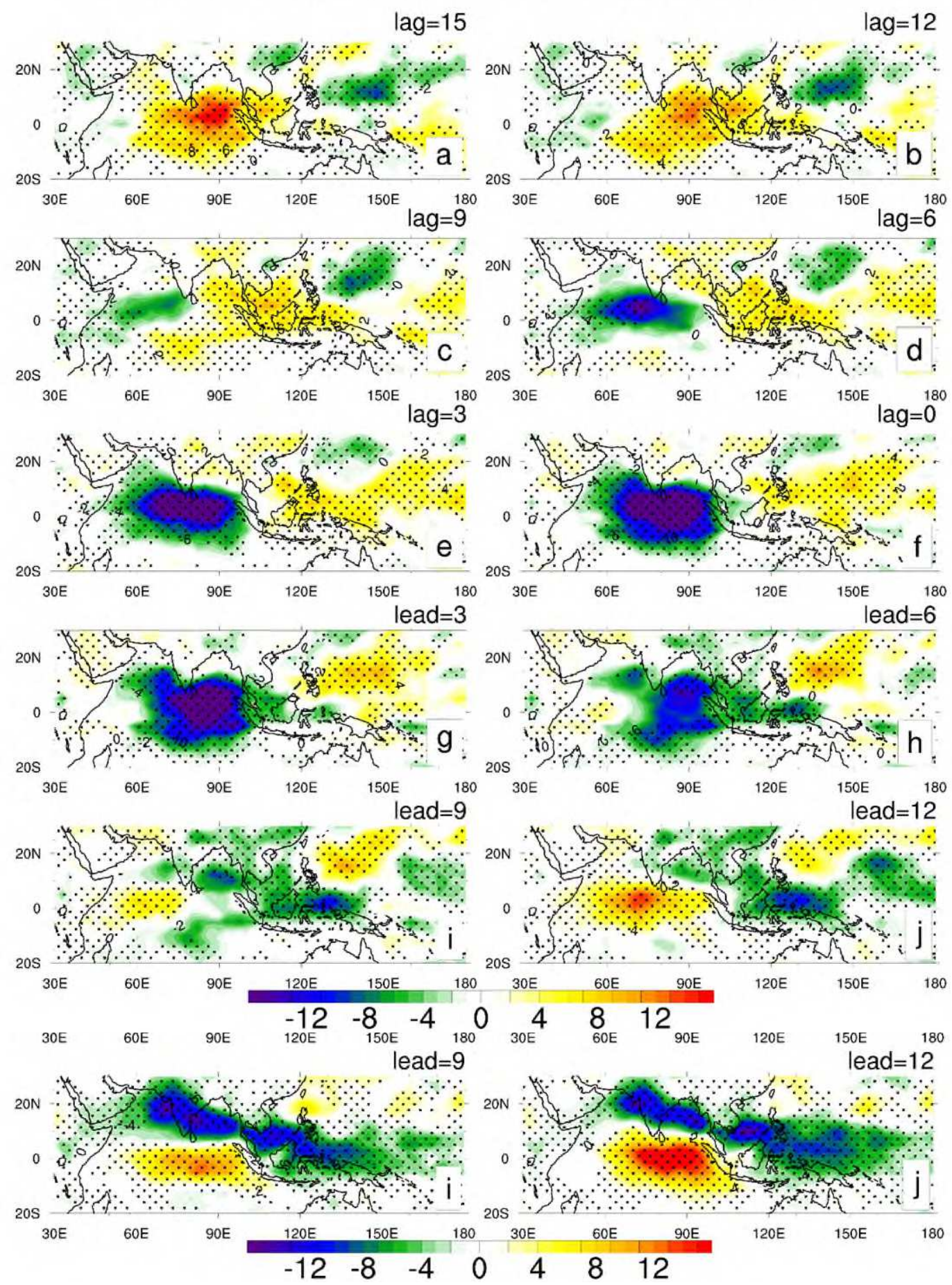

Fig. 4 Evolution composite of ISO filtered OLR anomalies $\left(\mathrm{W} / \mathrm{m}^{2}\right)$ for nIOD years. The composite is constructed from 42 events across 10 nIOD years (Table 1), regions with significance level greater than 95\% 


\section{Composite of ISO filtered OLR anomaly for pIOD years}
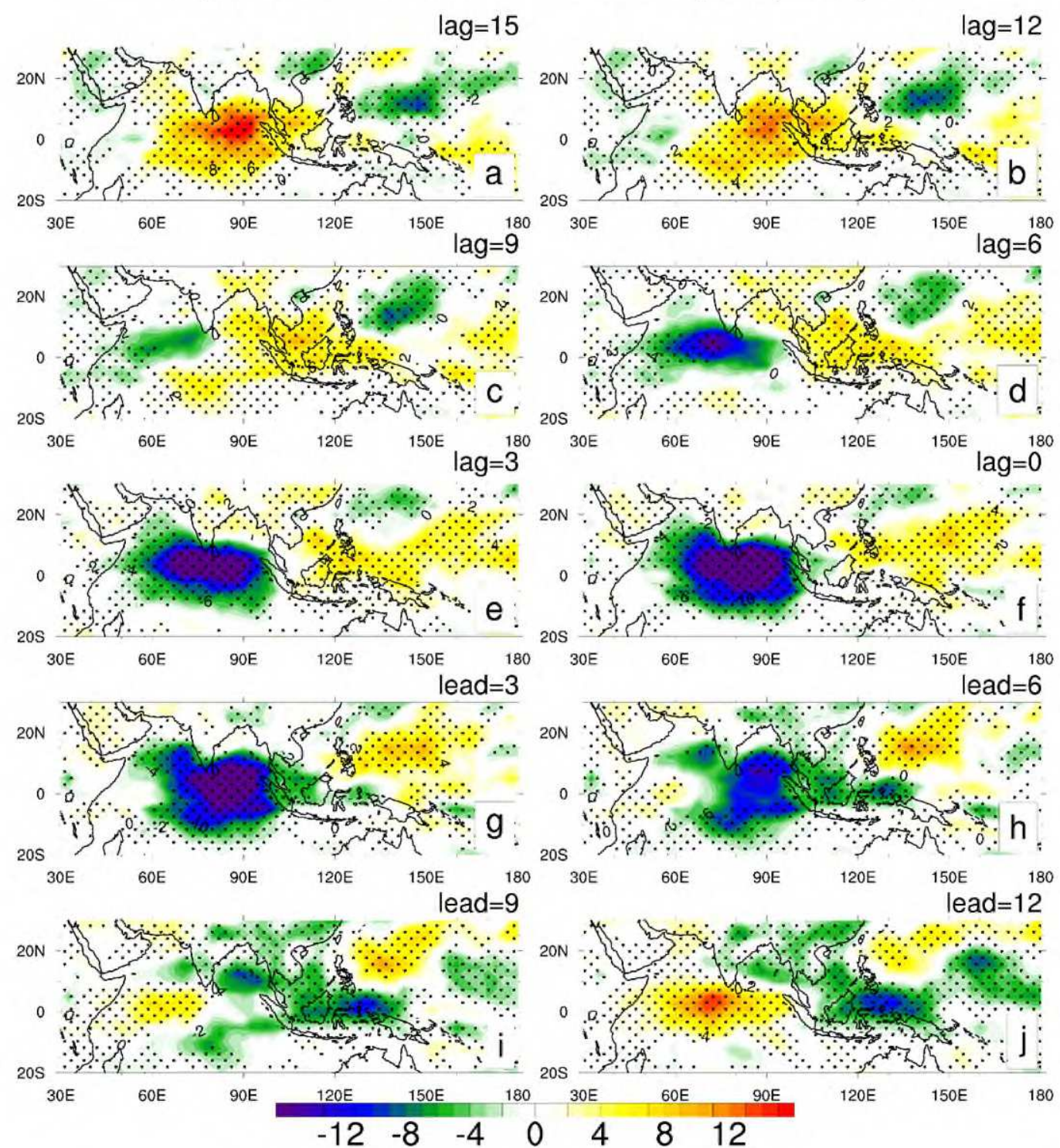

Fig. 5 Evolution composite of ISO filtered OLR anomalies $\left(\mathrm{W} / \mathrm{m}^{2}\right)$ for pIOD years. The composite is constructed from 25 events across 7 pIOD years (Table - 1), regions with significance level greater than $95 \%$ 


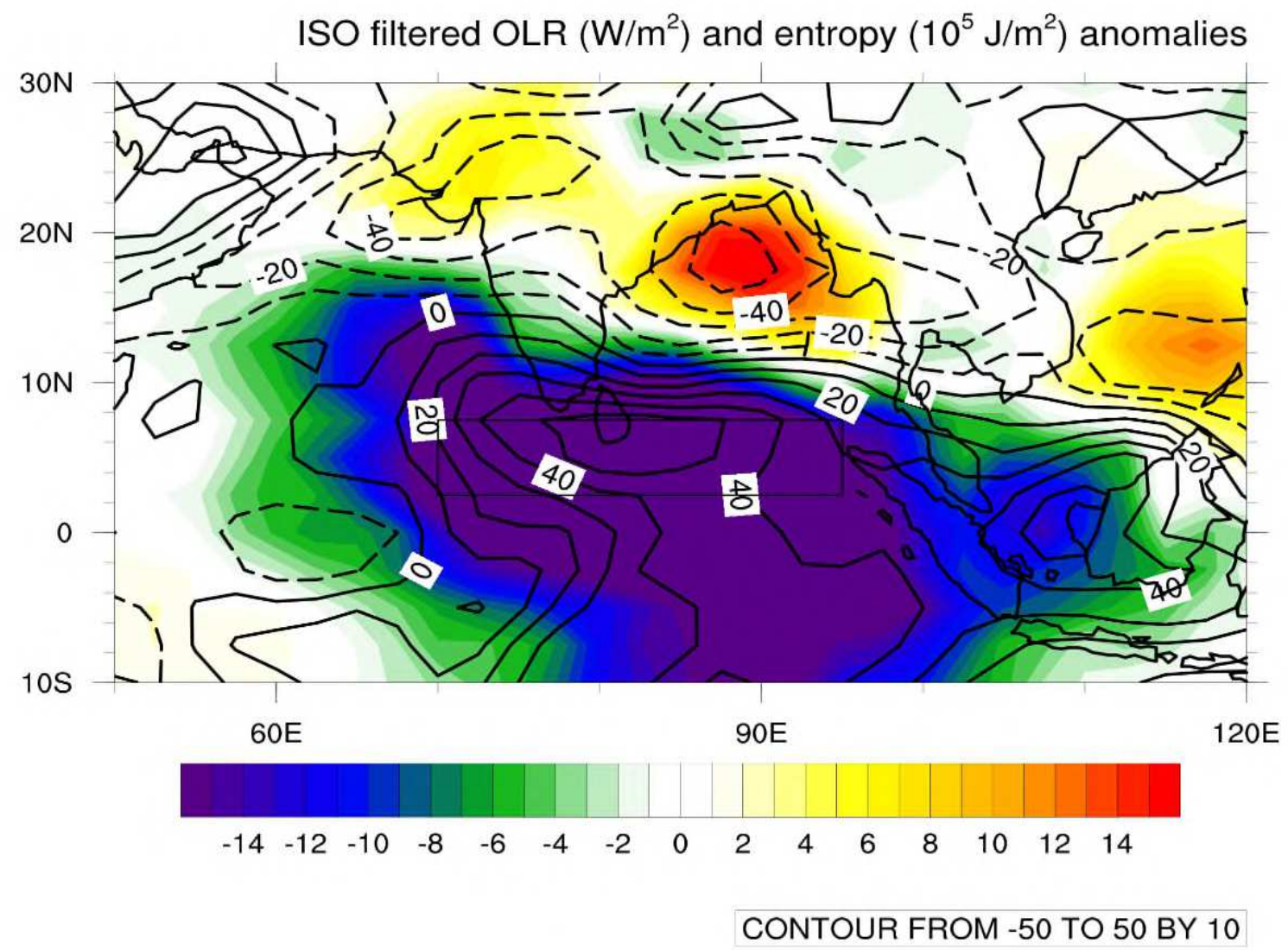

Fig. 6 Composite of ISO filtered OLR (colour shaded contours, W/m²) and moist entropy (lined contours, $10^{5}$ $\mathrm{J} / \mathrm{m}^{2}$ ) anomalies corresponding to the day of ISO OLR minima over region $2.5^{\circ} \mathrm{N}-7.5^{\circ} \mathrm{N}$ and $70^{\circ} \mathrm{E}-95^{\circ} \mathrm{E}$ 


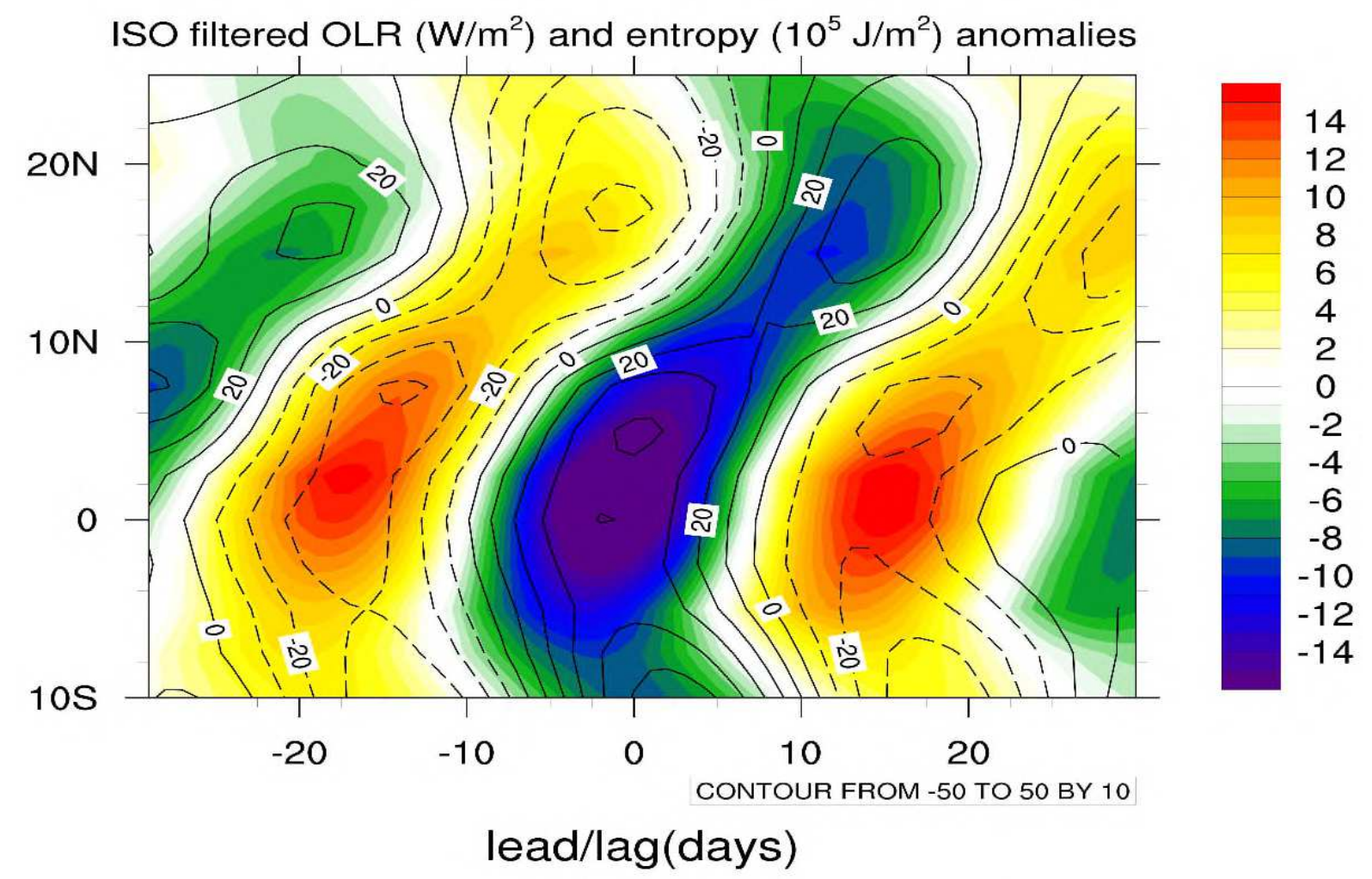

Fig. 7 Latitude - time composite evolution of ISO filtered OLR anomalies (colour shaded contours, $\mathrm{W} / \mathrm{m}^{2}$ ) and moist entropy anomalies (lined contours, $10^{5} \mathrm{~J} / \mathrm{m}^{2}$ ) averaged across longitudes $70^{\circ} \mathrm{E}-95^{\circ} \mathrm{E}$. Lag (days) corresponds to those shown in Fig. 4. The solid lined and dashed lines represent the positive and negative anomalies of moist entropy, respectively. 


\section{a) Entropy tendency}

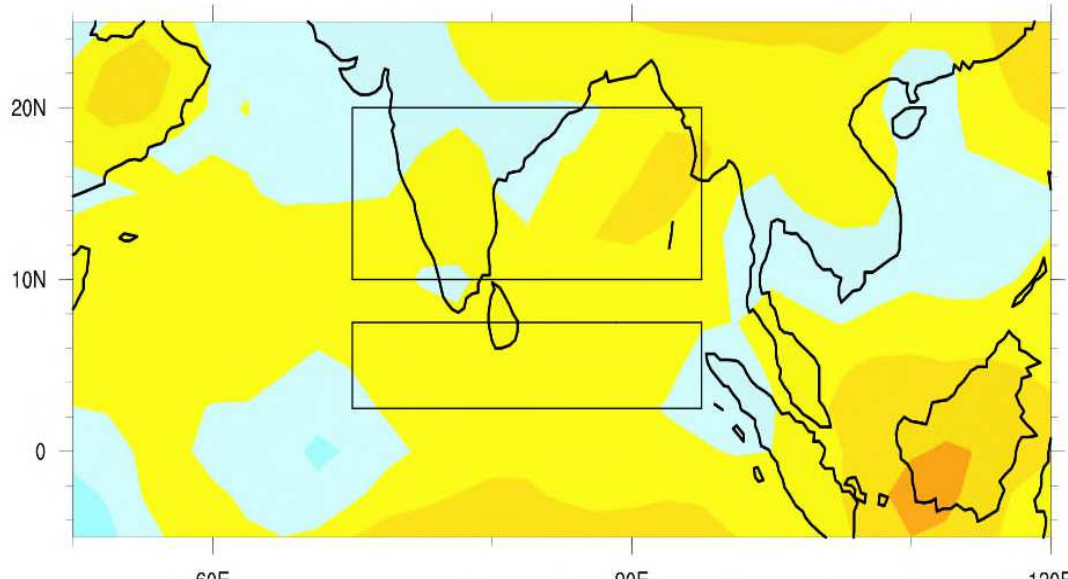

801

60E

goE

$120 \mathrm{E}$

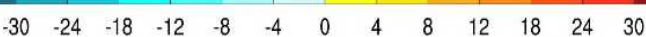

b) Horizontal advection

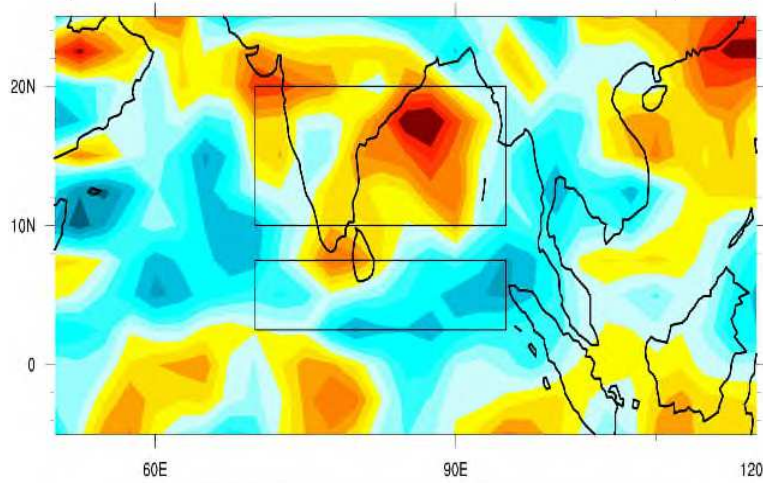

SOE

$\begin{array}{lllllllllllll}-30 & -24 & -18 & -12 & -8 & -4 & 0 & 4 & 8 & 12 & 18 & 24 & 30\end{array}$ $60 \mathrm{E}$ $90 \mathrm{E}$

$120 \mathrm{E}$

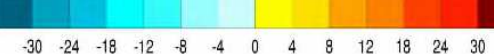

$\begin{array}{lllllllllllll}-30 & -24 & -18 & -12 & -8 & -4 & 0 & 4 & 8 & 12 & 18 & 24 & 30\end{array}$ c) Surface fluxes $f_{\text {ISO }}$

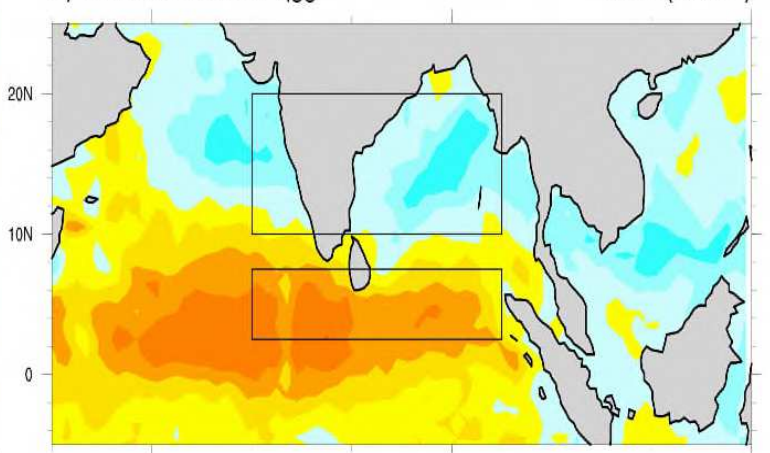

60E

90E

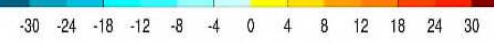

out

$\begin{array}{lllllllllllll}-30 & -24 & -18 & -12 & -8 & -4 & 0 & 4 & 8 & 12 & 18 & 24 & 30\end{array}$

$8 \cap 7$

d) Vertical advection $-10.044\left(\mathrm{~W} / \mathrm{m}^{2}\right)$

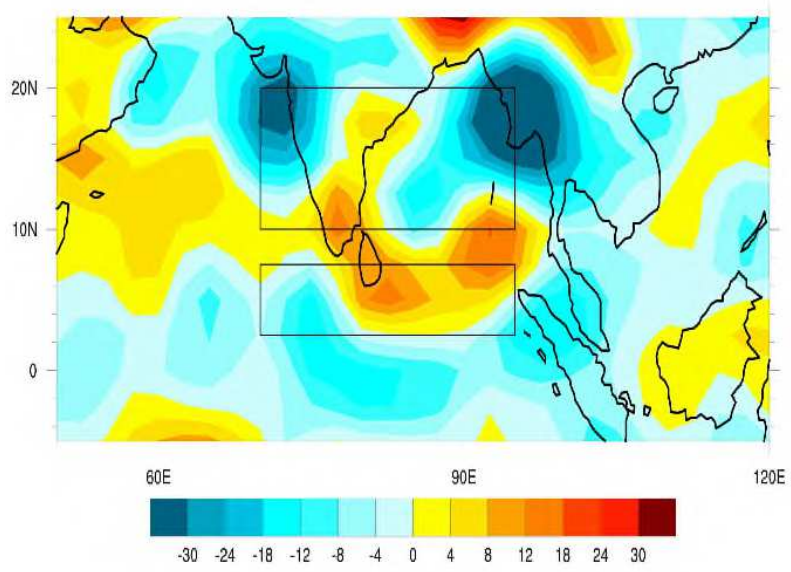


816 Fig. 8 Lag 0 patterns of a) entropy tendency $\left[\frac{\partial s}{\partial t}\right]_{I S O}$, b) horizontal advection $[-\bar{v} \cdot \nabla s]_{I s o}$, c) surface fluxes

$817 F_{I s o}$ and d) vertical advection $\left[-\omega \frac{\partial S}{\partial p}\right]_{I S O}$, all in $\left(\mathrm{W} / \mathrm{m}^{2}\right)$ for nIOD years. The region $2.5^{\circ} \mathrm{N}-7.5^{\circ} \mathrm{N}$ and $70^{\circ} \mathrm{E}-$

$81895^{\circ} \mathrm{E}$ (lower rectangle) shows the region over which ISO convection (OLR) is maximum (minimum) on lag 0,

819 the average of these terms over the $10^{\circ} \mathrm{N}-20^{\circ} \mathrm{N}$ and $70^{\circ} \mathrm{E}-95^{\circ} \mathrm{E}$ (upper rectangle) region are printed on top 820 right of each Figure.

821

822

823

824

825

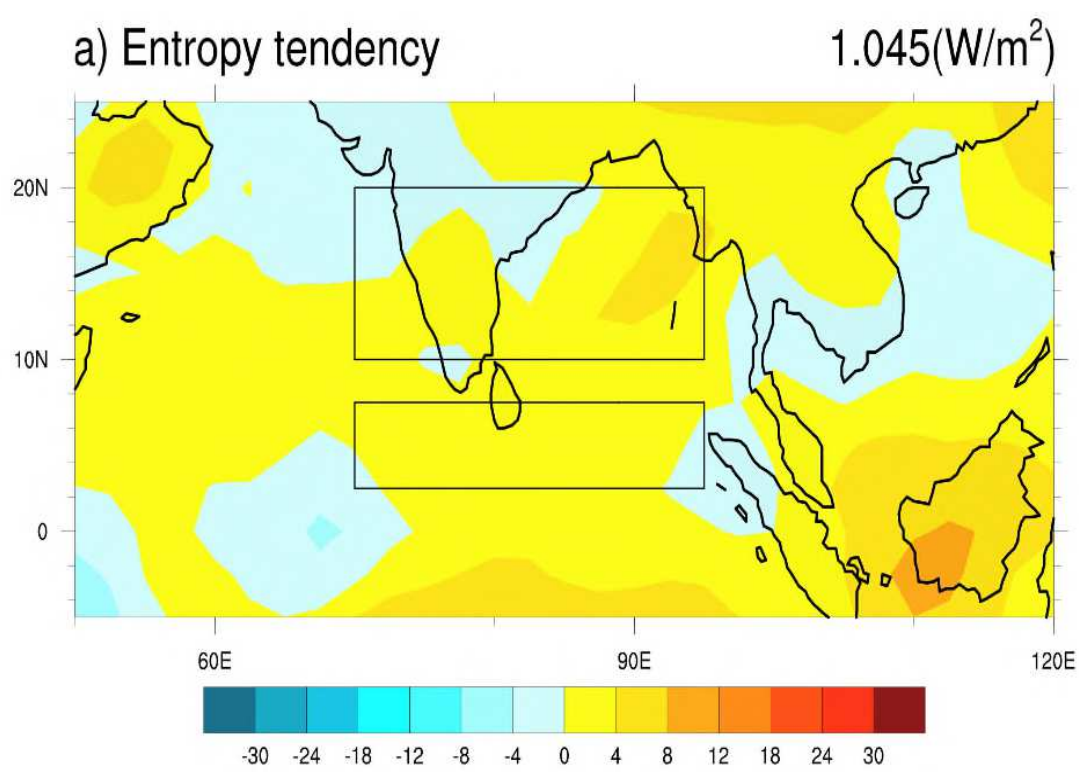

839
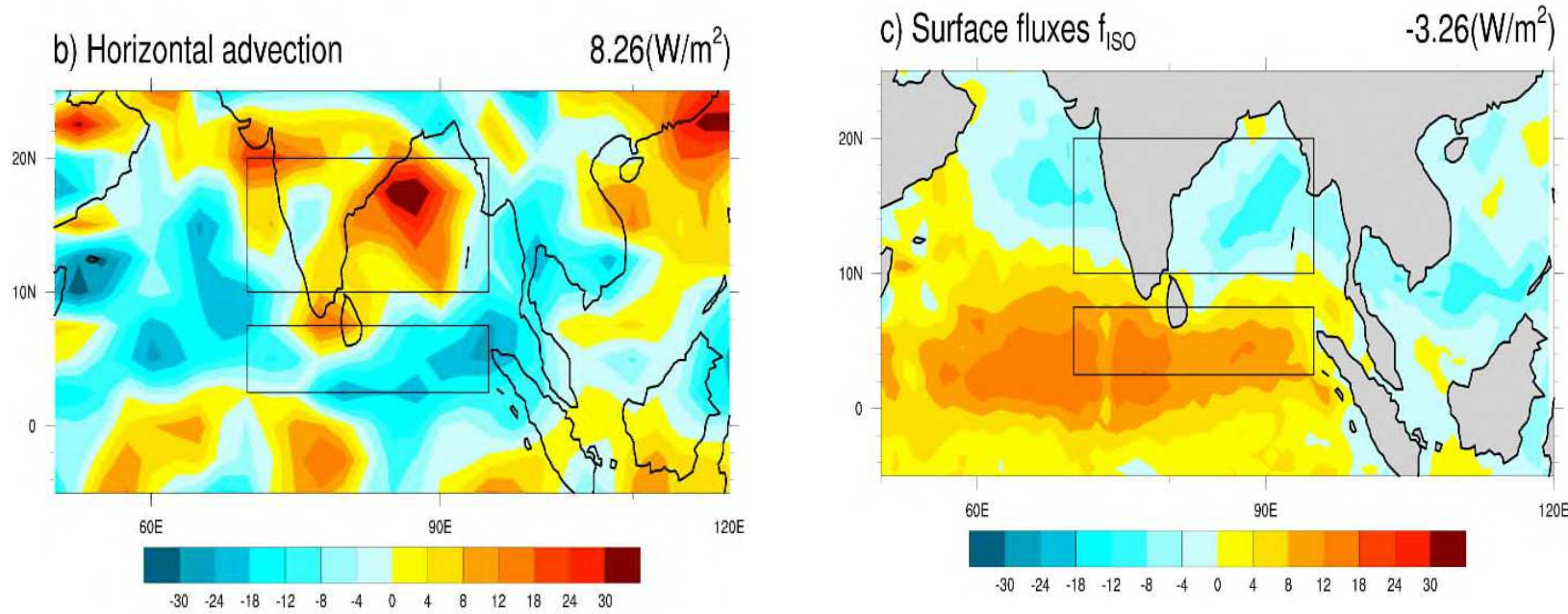

840 


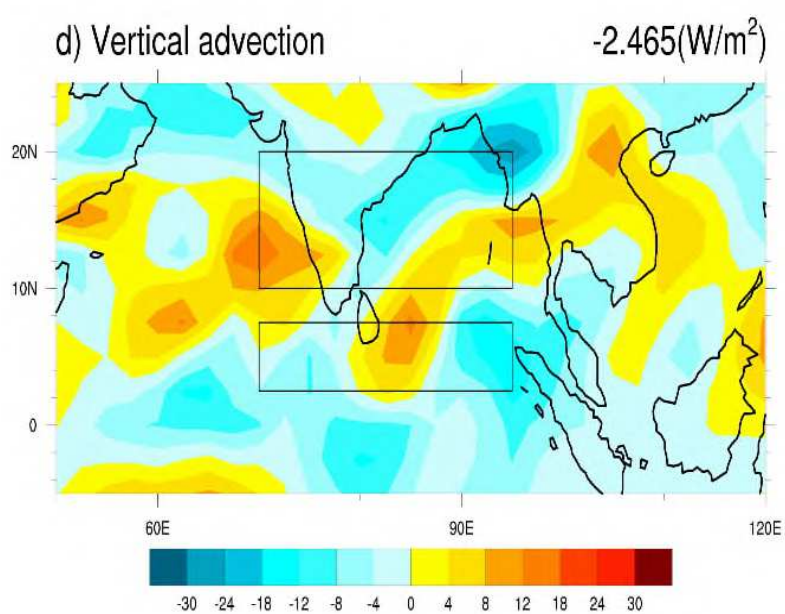

854

Fig. 9 Same as Fig. 8 but for pIOD years.

856
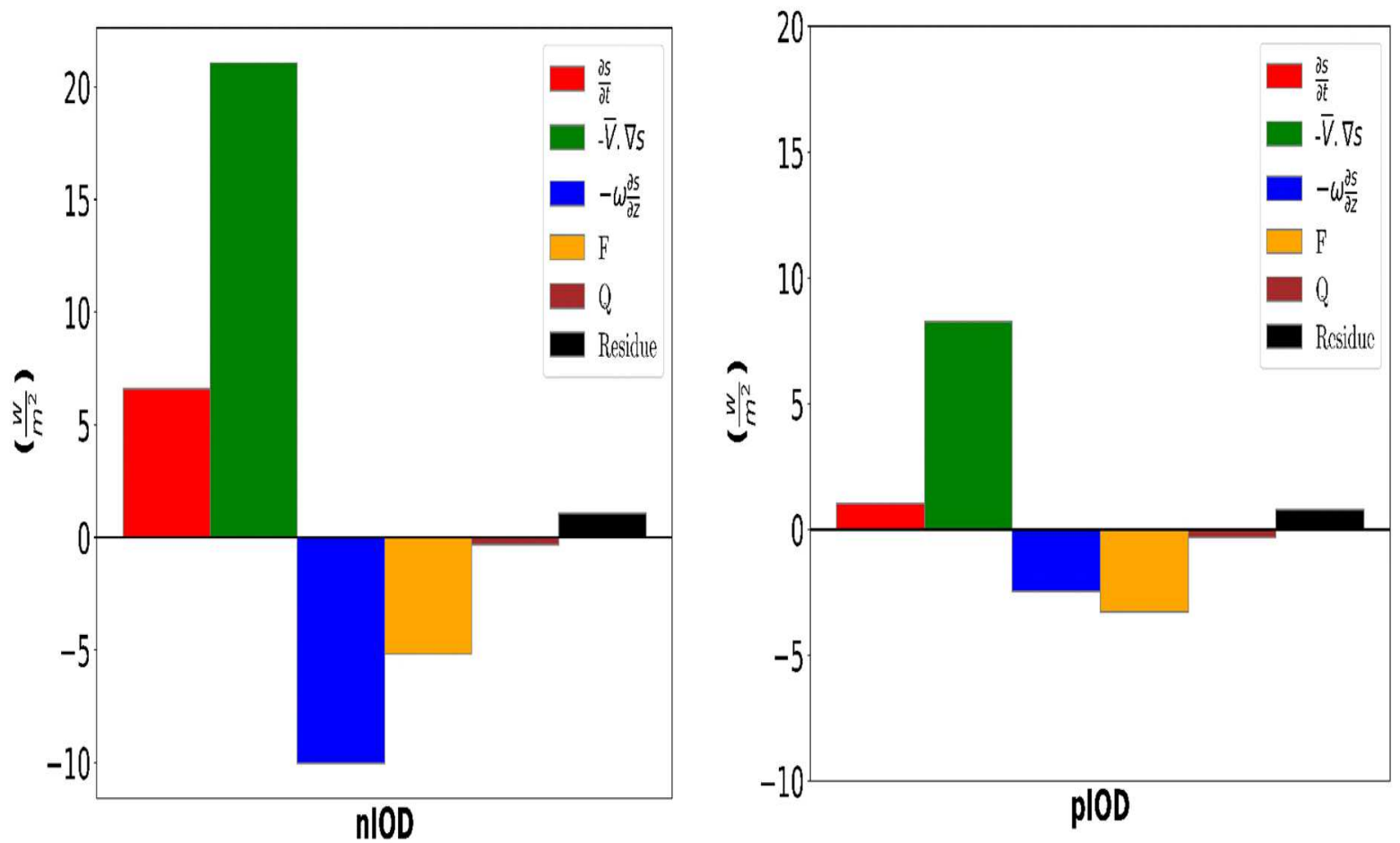

Fig. 10 Entropy budget (the average over the region $10^{\circ} \mathrm{N}-20^{\circ} \mathrm{N}, 70^{\circ} \mathrm{E}-95^{\circ} \mathrm{E}, \mathrm{W} / \mathrm{m}^{2}$ ) pertaining to Equation (5) on lag 0 for a) nIOD and b) pIOD years. The Q(radiative flux) term contains only the OLR component, the shortwave radiation component adds to the Residue. 

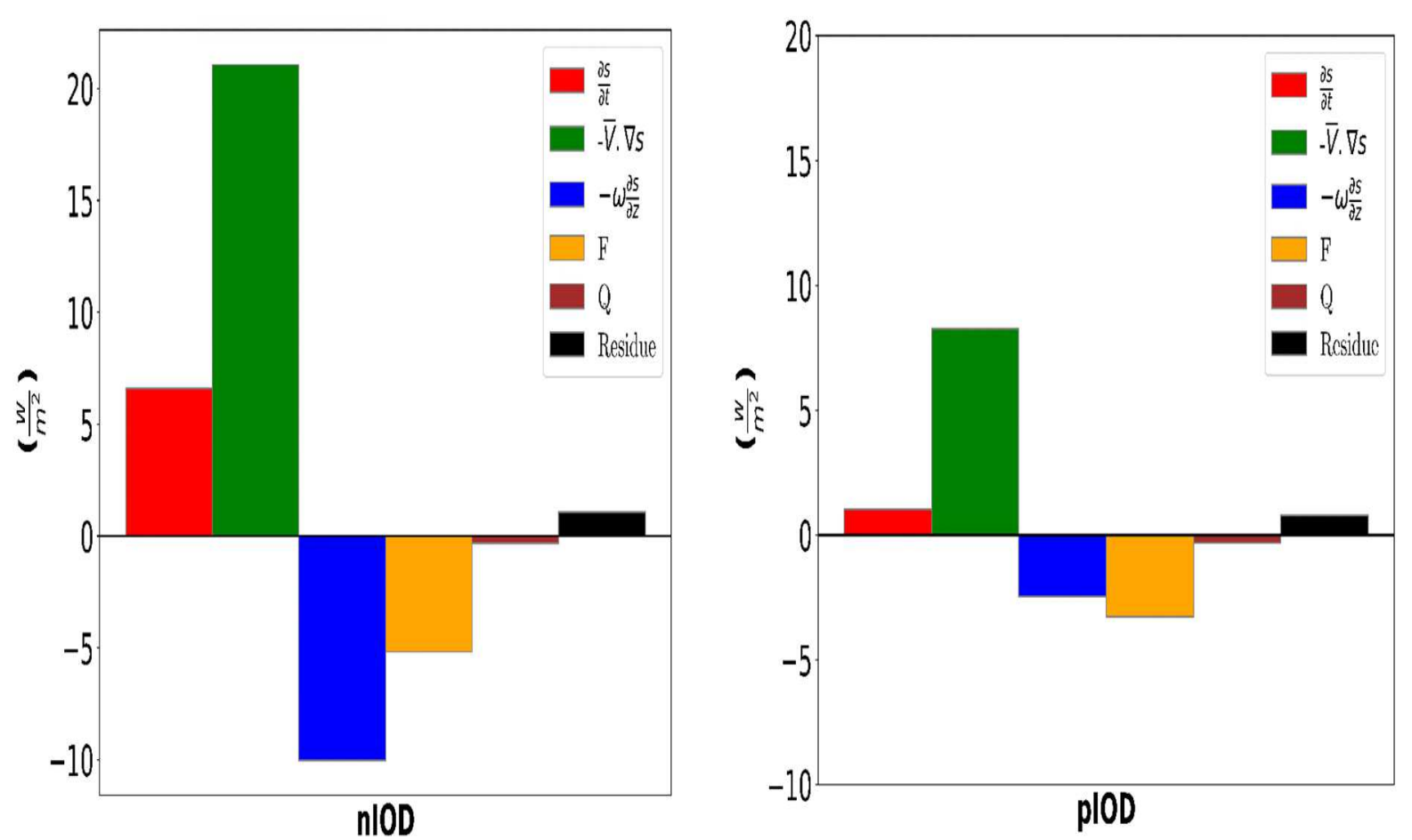

875

876

877

878

879

880

881

Fig. 11 The horizontal advection budget (the average over the region $10^{\circ} \mathrm{N}-20^{\circ} \mathrm{N}, 70^{\circ} \mathrm{E}-95^{\circ} \mathrm{E}, \mathrm{W} / \mathrm{m}^{2}$ )

882 pertaining to Equation (7) for a) nIOD years and b) pIOD years(right) corresponding to lag 0 (Fig. 4 and 5).

883

884 


\section{3}
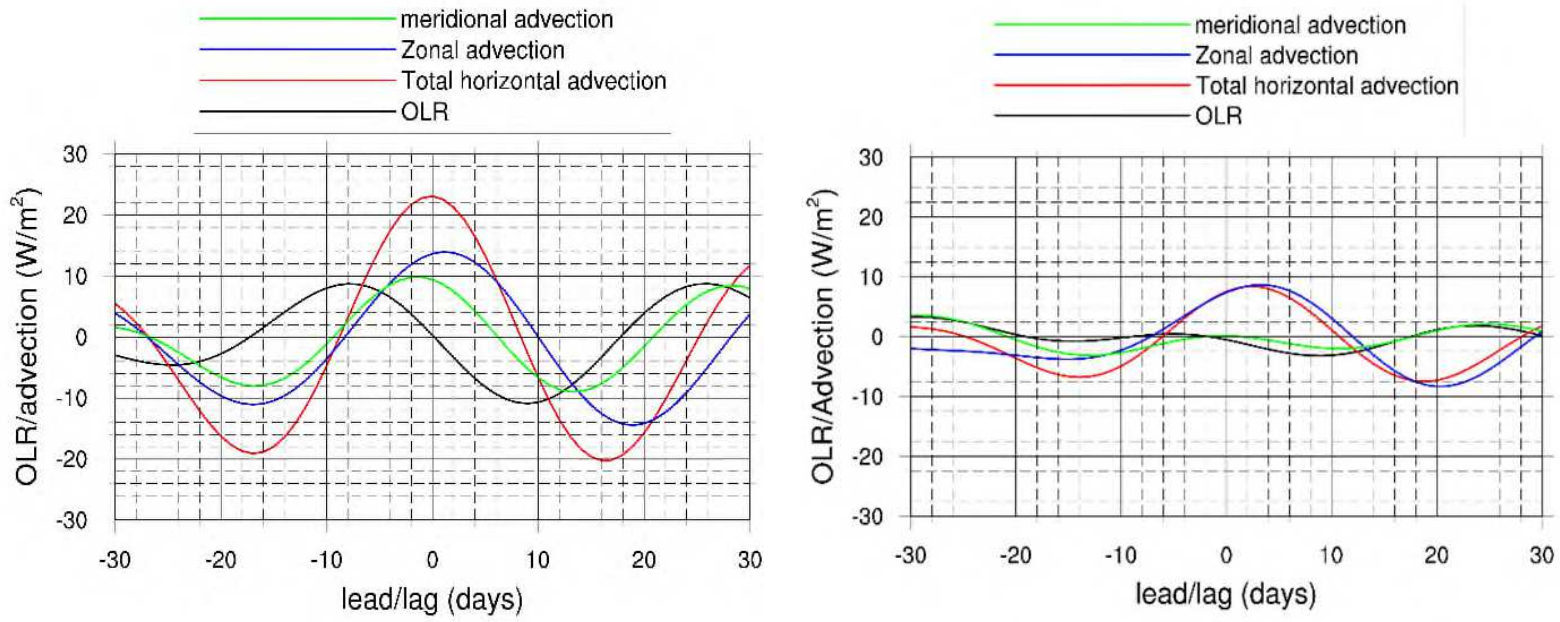

894

Fig. 12 The composite phase relationship between the horizontal advection (the average over the region $10^{\circ} \mathrm{N}-$ $20^{\circ} \mathrm{N}, 70^{\circ} \mathrm{E}-95^{\circ} \mathrm{E}$ ) and rainfall/OLR for all in W/m² for a) nIOD, b) pIOD years. Lag 0 corresponds to the convection centre at $5^{\circ} \mathrm{N}$ (Fig. 6).

898

899

900

901

902

903

904

905

906

907

908

909

910

911

912 


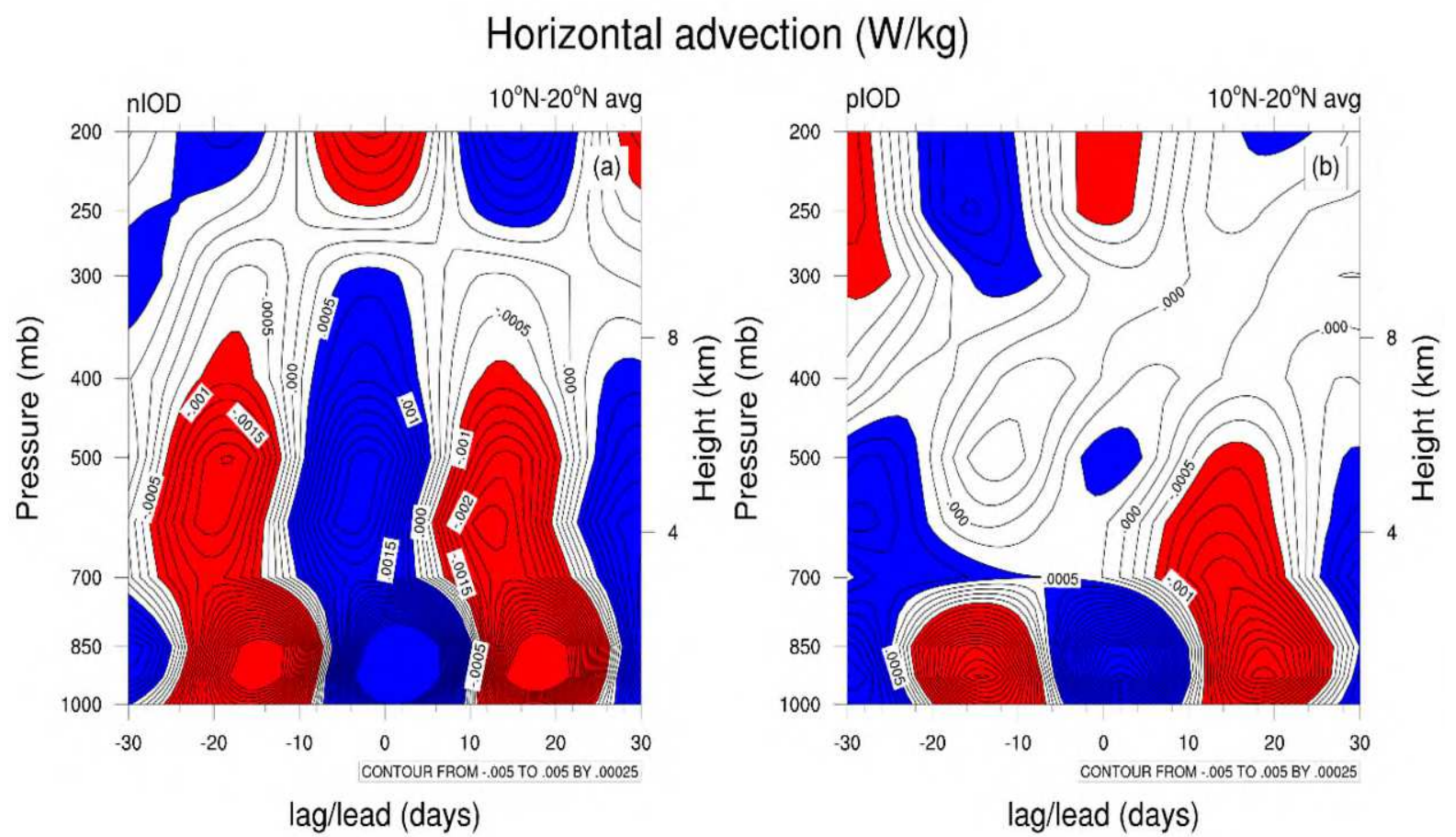

925 Fig. 13 Composite vertical structure of ISO filtered horizontal advection $(-\bar{v} \cdot \nabla s, \mathrm{~W} / \mathrm{kg})$ (averaged across $10^{\circ} N$ $926-20^{\circ} \mathrm{N}$ ) for a) nIOD and b) pIOD years, values above $5 \times 10^{-4} \mathrm{w} / \mathrm{kg}$ are shaded in blue and values below $-5 \times$ $92710^{-4} \mathrm{w} / \mathrm{kg}$ are shaded in red. $\mathrm{X}$ axis shows the lead/lag in days and $\mathrm{Y}$ axis shows pressure levels in millibar. 

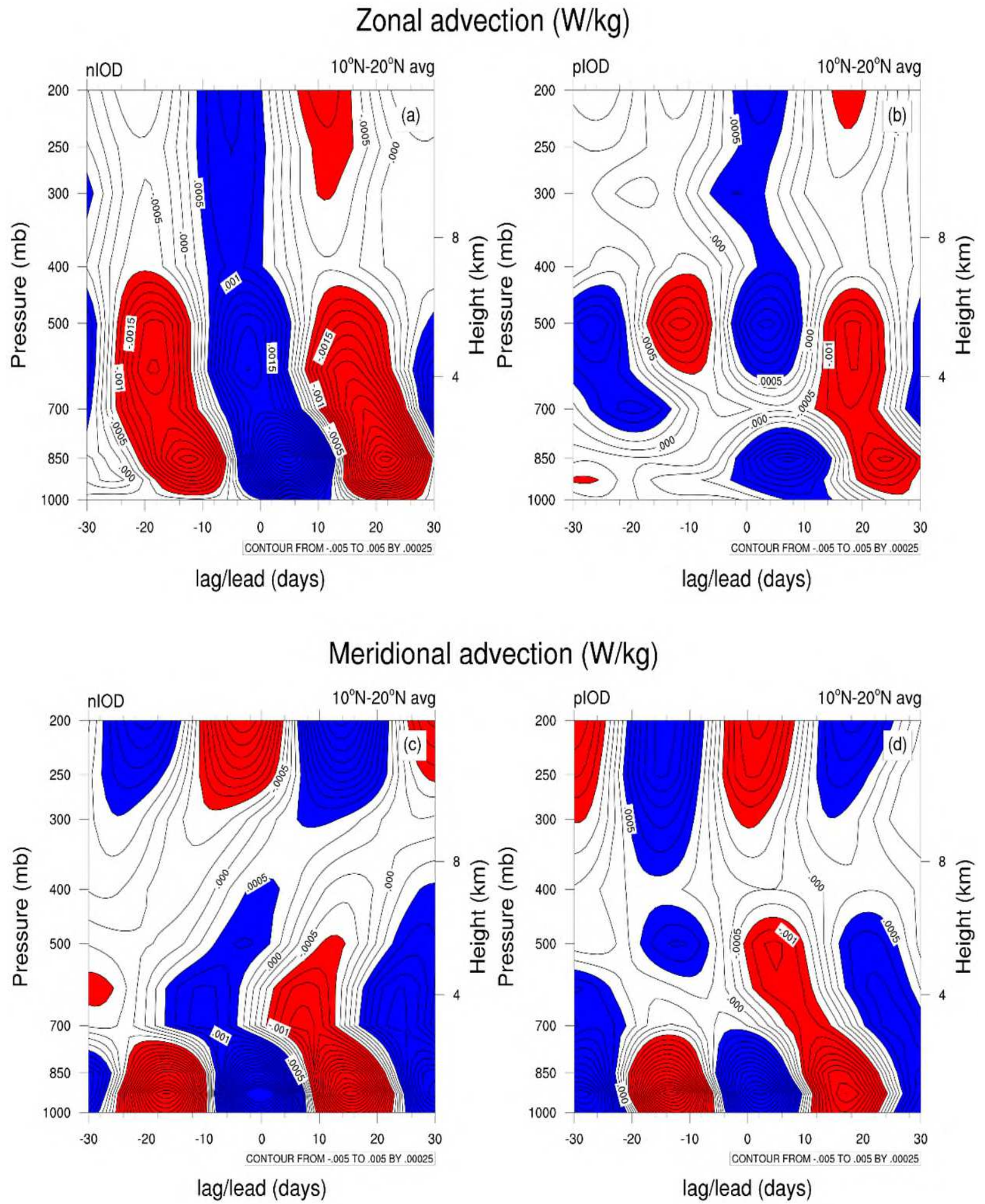

931 Fig. 14 Contributions of zonal $\left(-u \frac{\partial s}{\partial x}\right)$ and meridional advection $\left(-v \frac{\partial s}{\partial y}\right)(\mathrm{W} / \mathrm{kg})$ to the vertical structure of

932 horizontal advection (Fig. 13) for (a, c) nIOD and (b, d) pIOD years, like Fig. 13 values above $5 \times 10^{-4} \mathrm{~W} / \mathrm{kg}$ are shaded in blue and values below $-5 \times 10^{-4} \mathrm{~W} / \mathrm{kg}$ are shaded in red. $\mathrm{X}$ axis shows the lead/lag in days and 


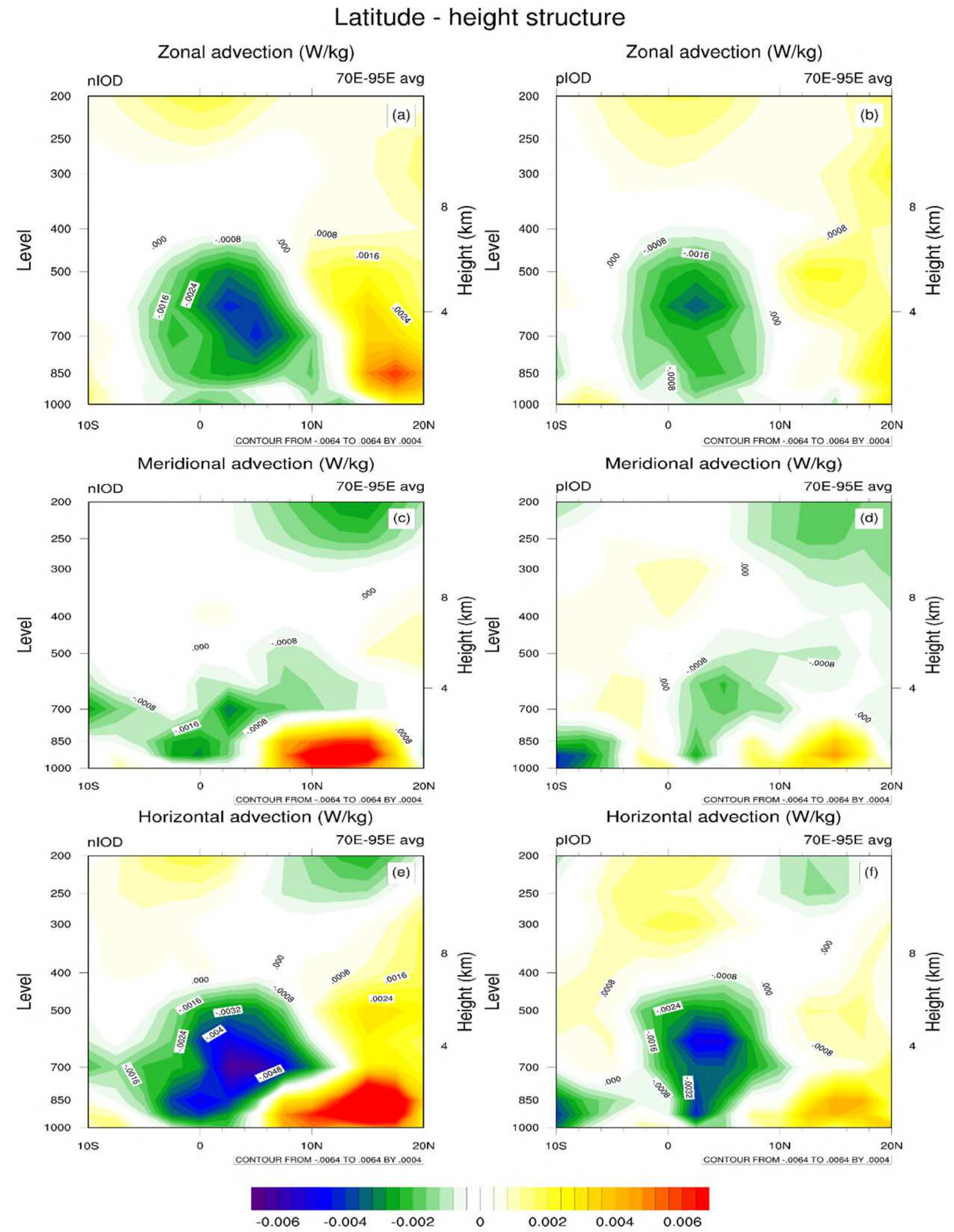

936 Fig. 15 Latitude - height structure of ISO filtered (a, b) total horizontal $(-\bar{v} \cdot \nabla s)$, (c, d) zonal $\left(-u \frac{\partial s}{\partial x}\right)$ and (e, f)

937 meridional $\left(-v \frac{\partial s}{\partial y}\right)$ advection anomalies (W/kg) respectively (averaged across $70^{\circ} E-95^{\circ} E$ ) for nIOD and

938 pIOD years corresponding to lag 0 . $\mathrm{X}$-axis shows the latitude and $\mathrm{Y}$ axis the pressure levels in millibar. 

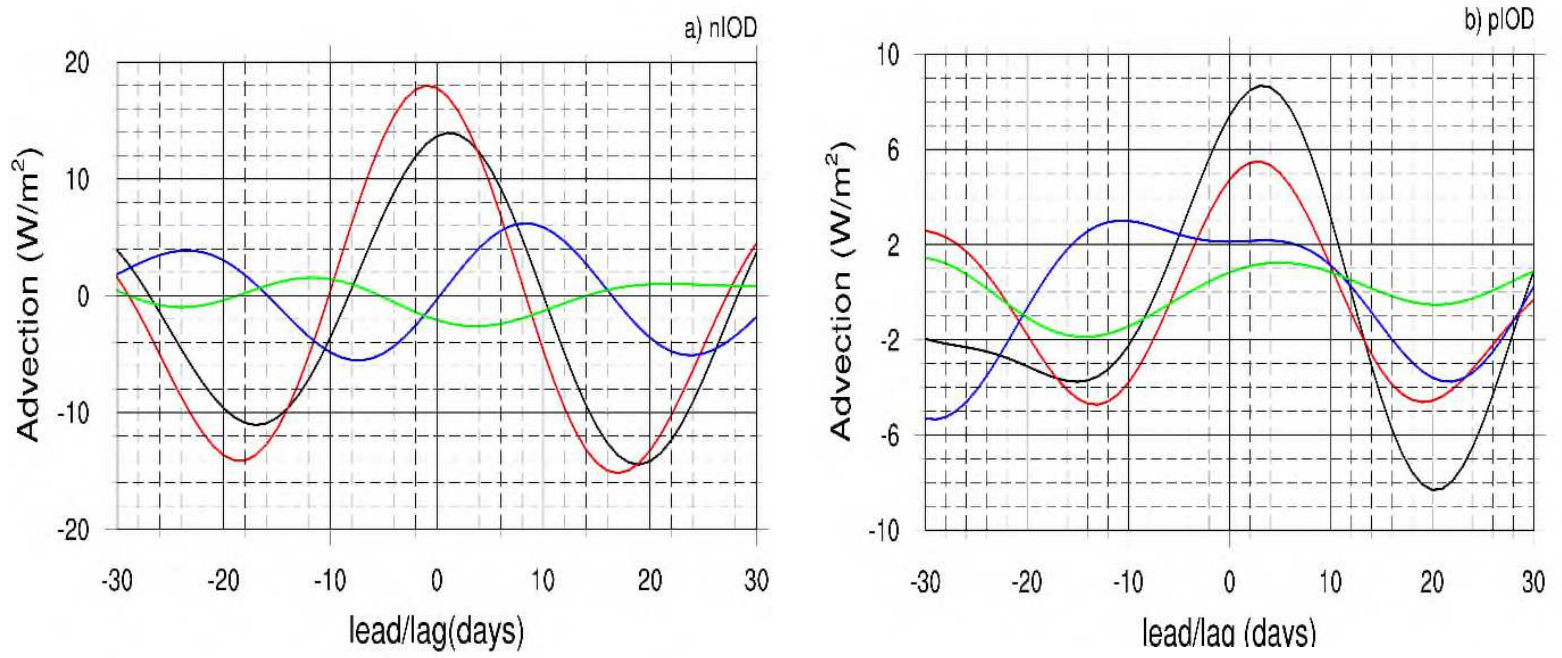

941

Fig. 16 Zonal advection (vertically integrated between $1000 \mathrm{hpa}-200 \mathrm{hpa}, \mathrm{W} / \mathrm{m}^{2}$ ) budget pertaining to

943 Equation (8) for a) nIOD and b) pIOD over the region $10^{\circ} \mathrm{N}-20^{\circ} \mathrm{N}, 70^{\circ} \mathrm{E}-95^{\circ} \mathrm{E}$, the black curve shows $u \frac{\partial S}{\partial x}$,

944 red curve shows $u^{\prime} \frac{\partial \bar{s}}{\partial x}$, blue curve shows $\bar{u} \frac{\partial s^{\prime}}{\partial x}$ and green curve shows $u^{\prime} \frac{\partial s^{\prime}}{\partial x}$, lag 0 corresponds to the day in Fig. 

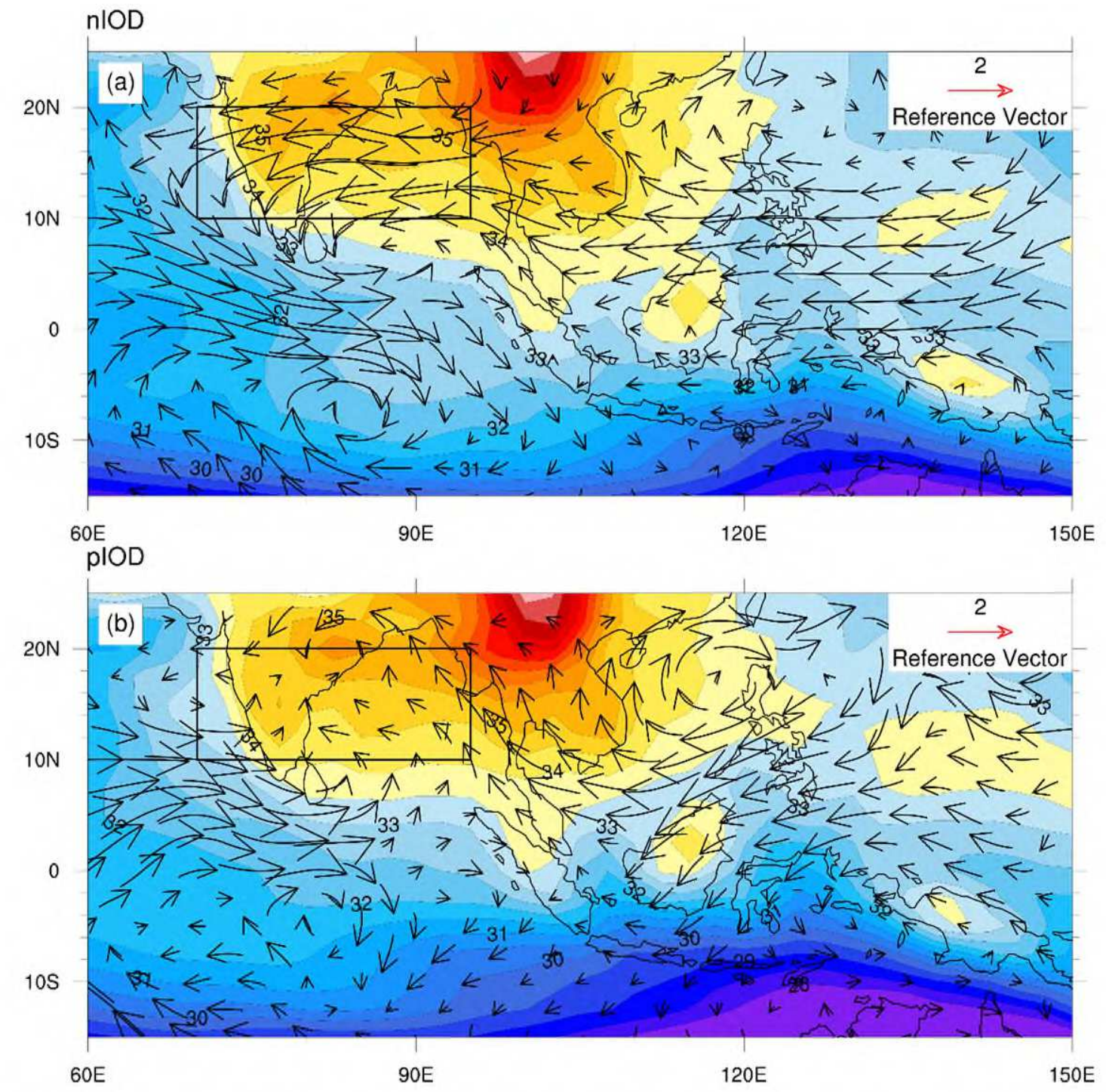

$\begin{array}{lllllllllllllllllllllll}28 & 28.5 & 29 & 29.5 & 30 & 30.5 & 31 & 31.5 & 32 & 32.5 & 33 & 33.5 & 34 & 34.5 & 35 & 35.5 & 36 & 36.5 & 37 & 37.5 & 38 & 38.5 & 39\end{array}$

955 

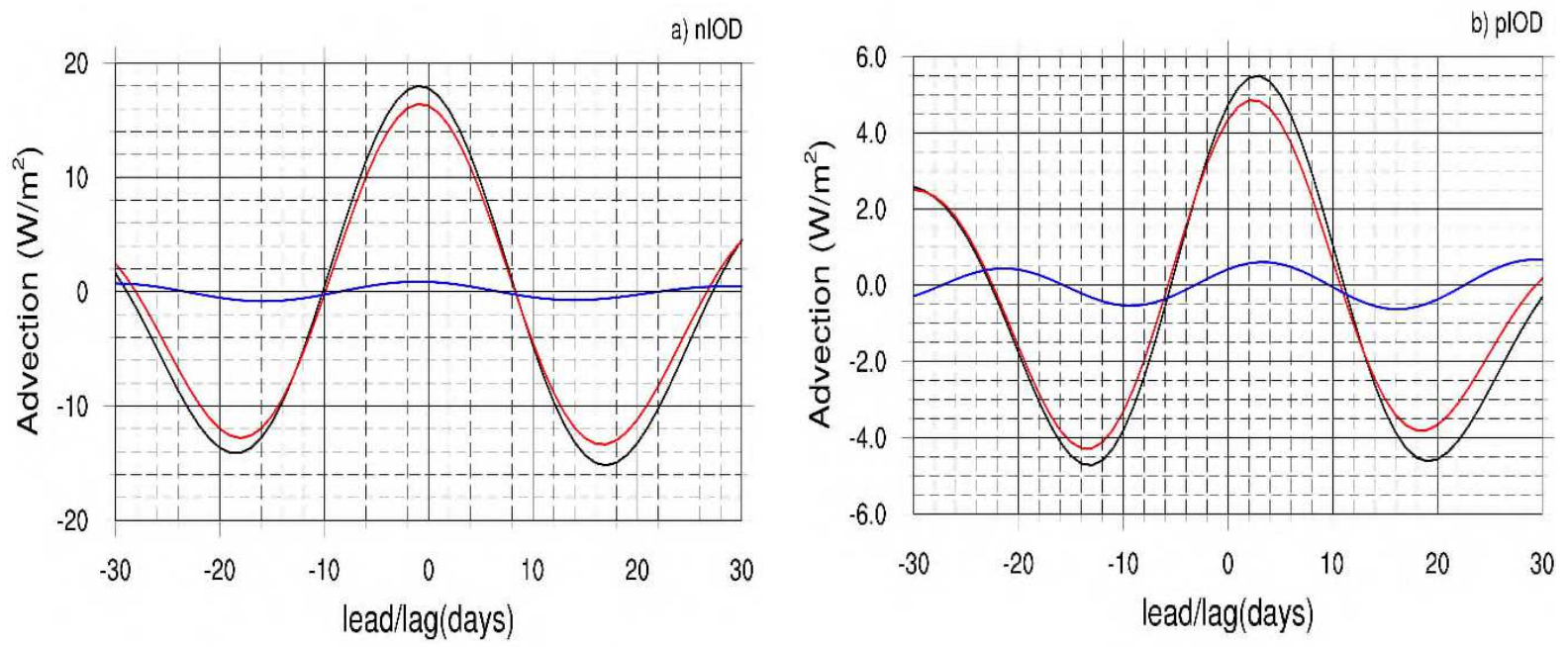

967

968 Fig. 18 Budget of ISO filtered $u^{\prime} \frac{\partial \bar{s}}{\partial x}$ term (vertically integrated between $1000 \mathrm{hpa}-200 \mathrm{hpa}$ ) for a) nIOD and b) pIOD years over the region $10^{\circ} N-20^{\circ} N, 70^{\circ} E-95^{\circ} E$, black curve shows $u^{\prime} \frac{\partial \bar{s}}{\partial x}$, red and blue curves show $u_{l f} \frac{\partial \bar{s}}{\partial x}$ and $u_{h f} \frac{\partial \bar{s}}{\partial x}$ respectively (Equation (11)), lag 0 corresponds to the day in Fig. 6 (Note that the scales on Yaxis are different for $a$ ) and $b$ )). 

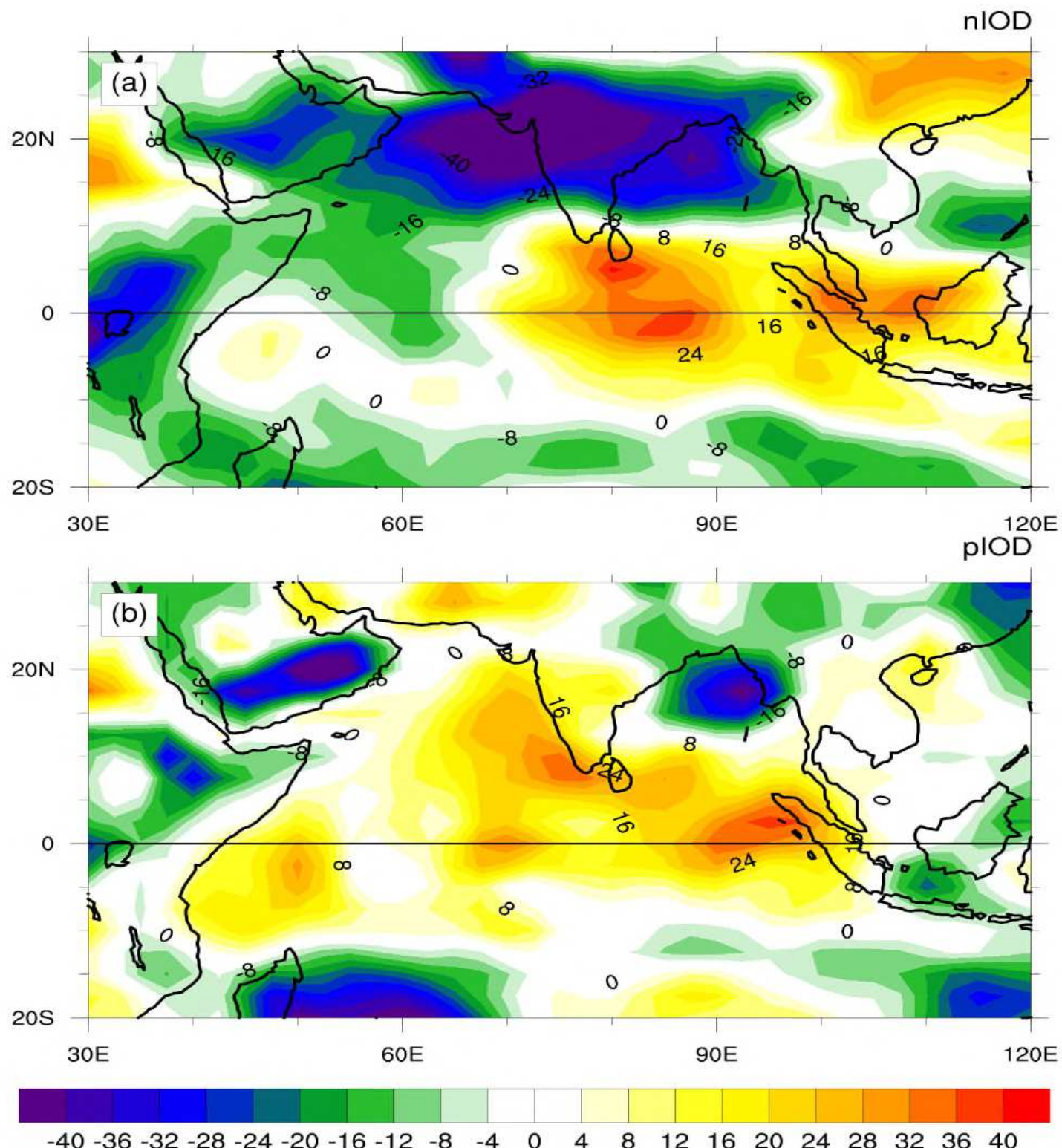

Fig. 19 ISO filtered entropy $\left(10^{5} \mathrm{~J} / \mathrm{m}^{2}\right.$, vertically integrated between $925 \mathrm{hpa}-500 \mathrm{hpa}$ levels) anomaly pattern corresponding to lag 5 days (Fig. 4 and 5) for a) nIOD and b) pIOD years. The bold black line shows the equator. 


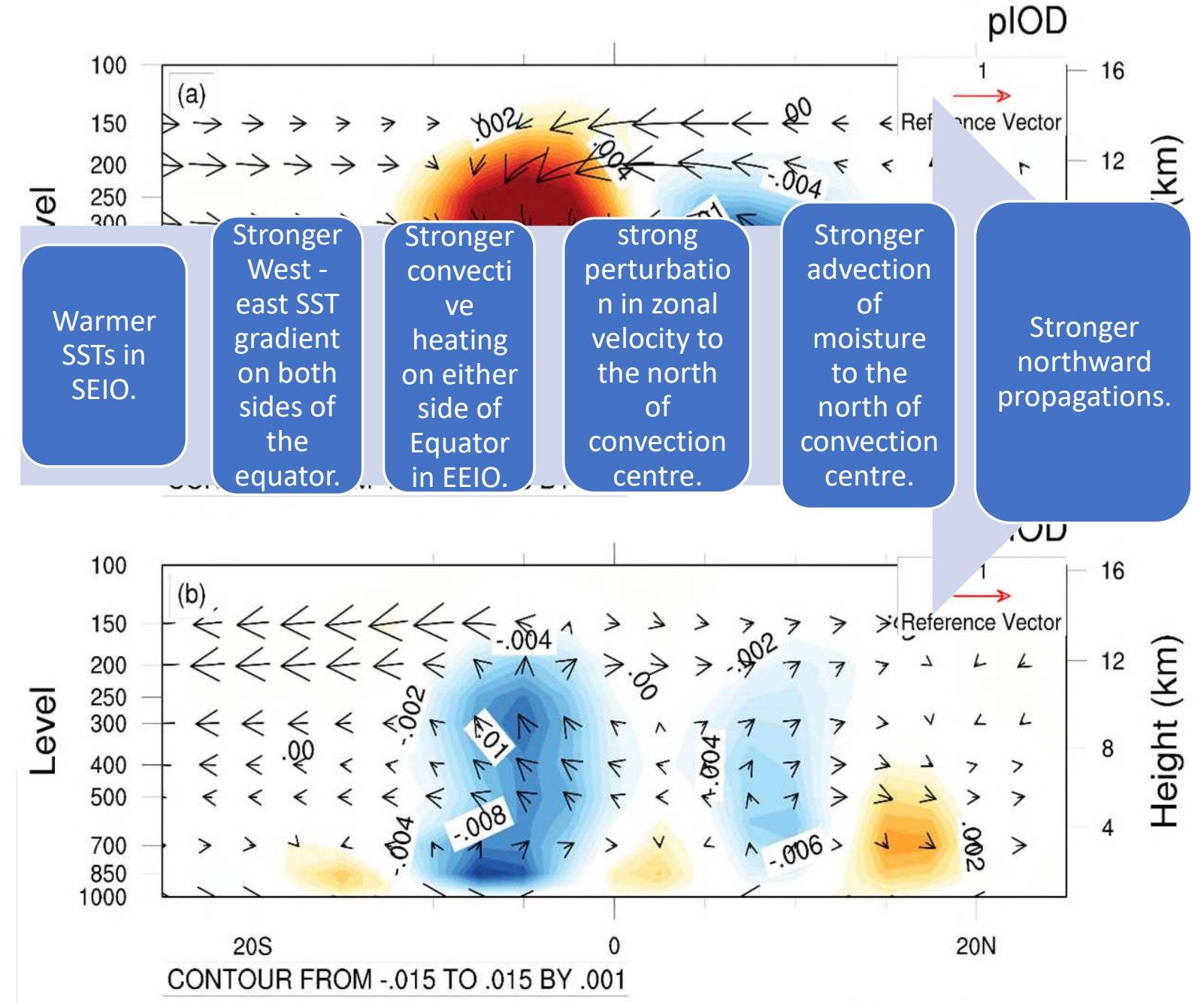

\begin{tabular}{llllllllllll|l}
\hline & & & & & & & & & & & & \\
\hline
\end{tabular}

1006

1007

1008

1009

1010

1011

1012

1013

1014

1015

1016 

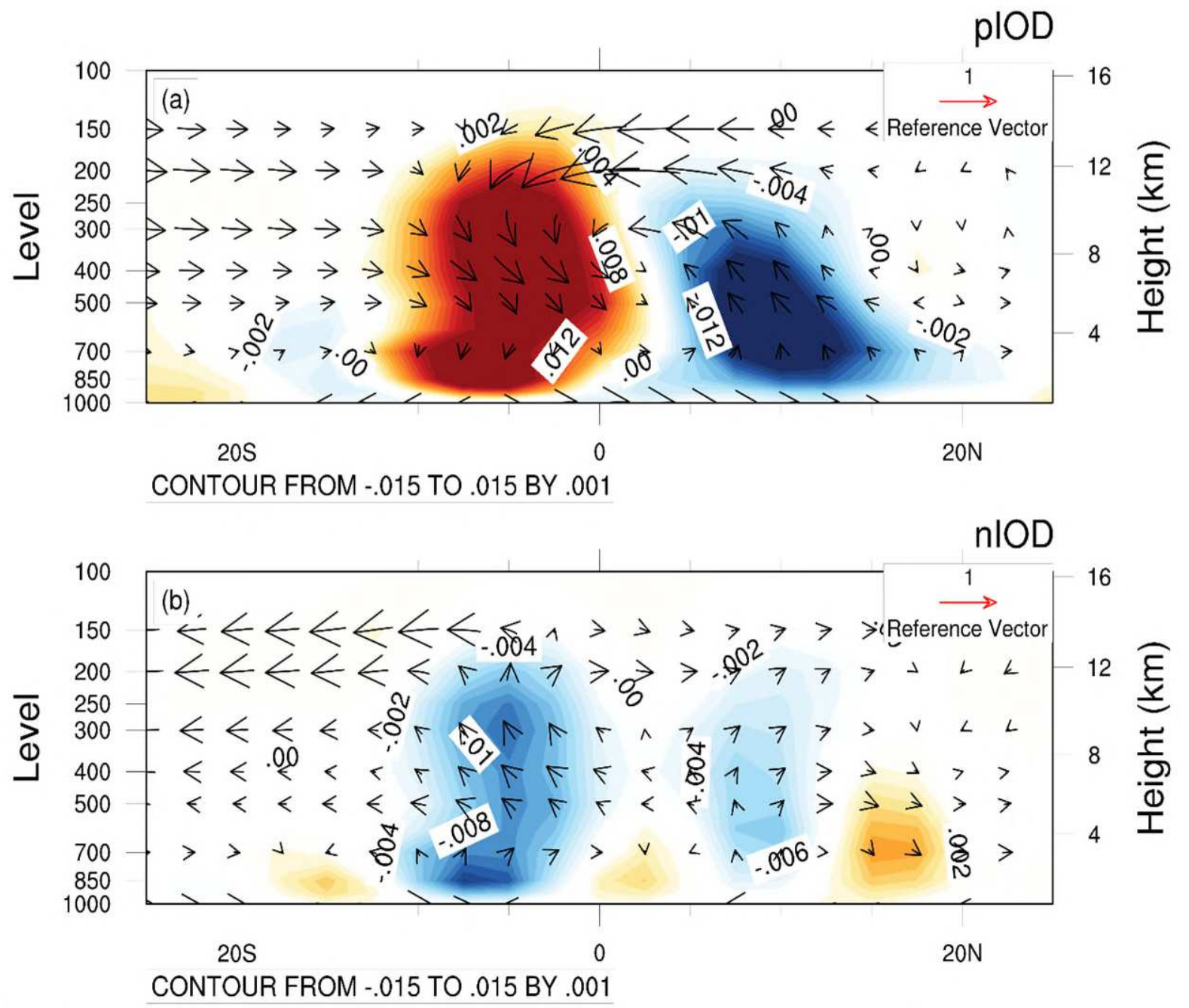

Fig. 21 The JJAS mean anomaly of pressure vertical velocity (pa/s, shaded) and meridional circulation (m/s, 1019 vectors), for a) pIOD and b) nIOD years. The vertical velocity scale has been enhanced by a factor of 100 (in the vector plot) for easy visualisation. The anomalies are averaged across $70^{\circ} \mathrm{E}-95^{\circ} \mathrm{E}$ longitudes. 


\section{Supplementary Files}

This is a list of supplementary files associated with this preprint. Click to download.

- supplement.docx 